\title{
Application of Decision Theory methods for a soil classification in the Community of Madrid (Spain)
}

\author{
José M. Antón · Ana M. Tarquis · Juan B. Grau • \\ Elena Sánchez $\cdot$ Antonio Saa $\cdot$ Mari-Cruz Díaz
}

\begin{abstract}
A land classification method was designed for the Community of Madrid (CM), which has lands suitable for either agriculture use or natural spaces. The process started from an extensive previous CM study that contains sets of land attributes with data for 122 types and a minimum-requirements method providing a land quality classification (SQ) for each land. Borrowing some tools from Operations Research (OR) and from Decision Science, that SQ has been complemented by an additive valuation method that involves a more restricted set of 13 representative attributes analysed using Attribute Valuation Functions to obtain a quality index, QI, and by an original composite method that uses a fuzzy set procedure to obtain a combined quality index, CQI, that contains relevant information from both the SQ and the QI methods.
\end{abstract}

Keywords Pedology · Soil science · Qualification · Classification · Soil quality · Land capability · Valuation function · Additive valuation - Threshold requirements · Fuzzy set

\footnotetext{
Abbreviations

ADV attribute data value, corresponding to a $j$-attribute for an $i$-land, e.g. in Sect. 3.1.

AQI attribute quality index, value falling in a nominal range $(0,1)$, obtained using an AVF.

AVF attribute valuation function, to obtain an AQI from a $j$-attribute data ADV for an $i$-land.

CEC Cation Exchange Capability, used in "CEC attribute value" for an $i$-land.

$\mathrm{CM} \quad$ is used in this paper for Comunidad de Madrid.

CM study (Gallardo et al. 2005), survey for CM that is the primary source for the methods in the paper.
}

J.M. Antón (四) · A.M. Tarquis · J.B. Grau · E. Sánchez

Dto. Matemática Aplicada, E.T.S. de Ing. Agrónomos, U.P.M., Av. Complutense s/n, 28040 Madrid, Spain

e-mail: josemanuel.anton@upm.es

A. Saa - M.-C. Díaz

Dto. Edafología, E.T.S. de Ing. Agrónomos, U.P.M., Av. Complutense s/n, 28040 Madrid, Spain 
CQI combined soil quality index, giving a "CQI value" for an $i$-land in nominal range $(0,1)$; used to obtain a "CQI qualification", also in "CQI method" to obtain "CQI values".

CP Compromise Programming.

DS Decision Science.

EC Electric conductivity, used in "EC attribute value" for an $i$-land.

ESP Exchange Sodium Percentage, used in "ESP attribute value" for an $i$-soil of an $i$-land.

ETS Escuela Técnica Superior in Spain, Technical School for Engineers, Superior is "of upper degree"; also its building and organisation or its entity with actual evolving organisation (e.g., with Bolonia plans).

ETSIA School of Agronomical Engineers of Madrid, from Escuela Técnica Superior de Ingenieros Agrónomos.

FAO Food and Agriculture Organisation of the United Nations.

LI limiting index, as $\delta_{i, k, j}$, defined in Sect. 4 by formula (4) to be used with formula (5).

MS EXCEL Microsoft EXCEL software.

MX missing index, Sect. 3.1, Sect. 4, indicating missing data values.

OR Operations Research.

QI quality index, defined in this paper getting a "QI value" $Q I$ in nominal range

$(0,1)$ for an $i$-soil with the related "QI method", to obtain a "QI qualification".

SCR Soil Sealing and Crusting Risk, attribute for SQ classification, Sect. 2.2, the Appendix.

SQ soil quality, refers mostly to the "SQ classification" in "SQ classes", with $S Q$ index being (I to IX) or (1 to 9), appears in the "SQ method" to obtain them, in the "SQ authors" of it, and also in "SQ criteria or attributes" corresponding to data for that method.

SAR Sodium Absorption Rate, used in "SAR attribute" value for an $i$-soil of an $i$-land.

SS Soil Science.

UPM Universidad Politécnica de Madrid.

USDA United States Department of Agriculture.

USLE Universal Soil Loss Equation, used in "USLE-C attribute" (elsewhere found in an USLE/RUSLE acronym).

\section{Introduction}

Although Soil Science (SS) is of a primarily experimental nature, some methods from Decision Science (DS) and methods related to Operations Research (OR) offer applicable tools. Some of them have been adopted in this study to produce land classification indexes representing the quality of lands of a given region, mainly as a tool for regional planning. The source of data, formats and goals was a land-use CM study (Gallardo et al. 2005) of the soil and climate of the "Comunidad autónoma de Madrid" (Community of Madrid, CM in the following) including a CM document, backgrounds, data and maps. That document contains a traditional classification of the lands of the CM by land quality (SQ) depending on suitability for uses such as farming, forestry or conservation, based on minimum requirements for land attributes. It includes a specific selection of types of lands and of attributes for each one, assessed based on measures or on evaluation of soil properties. As these SQ 


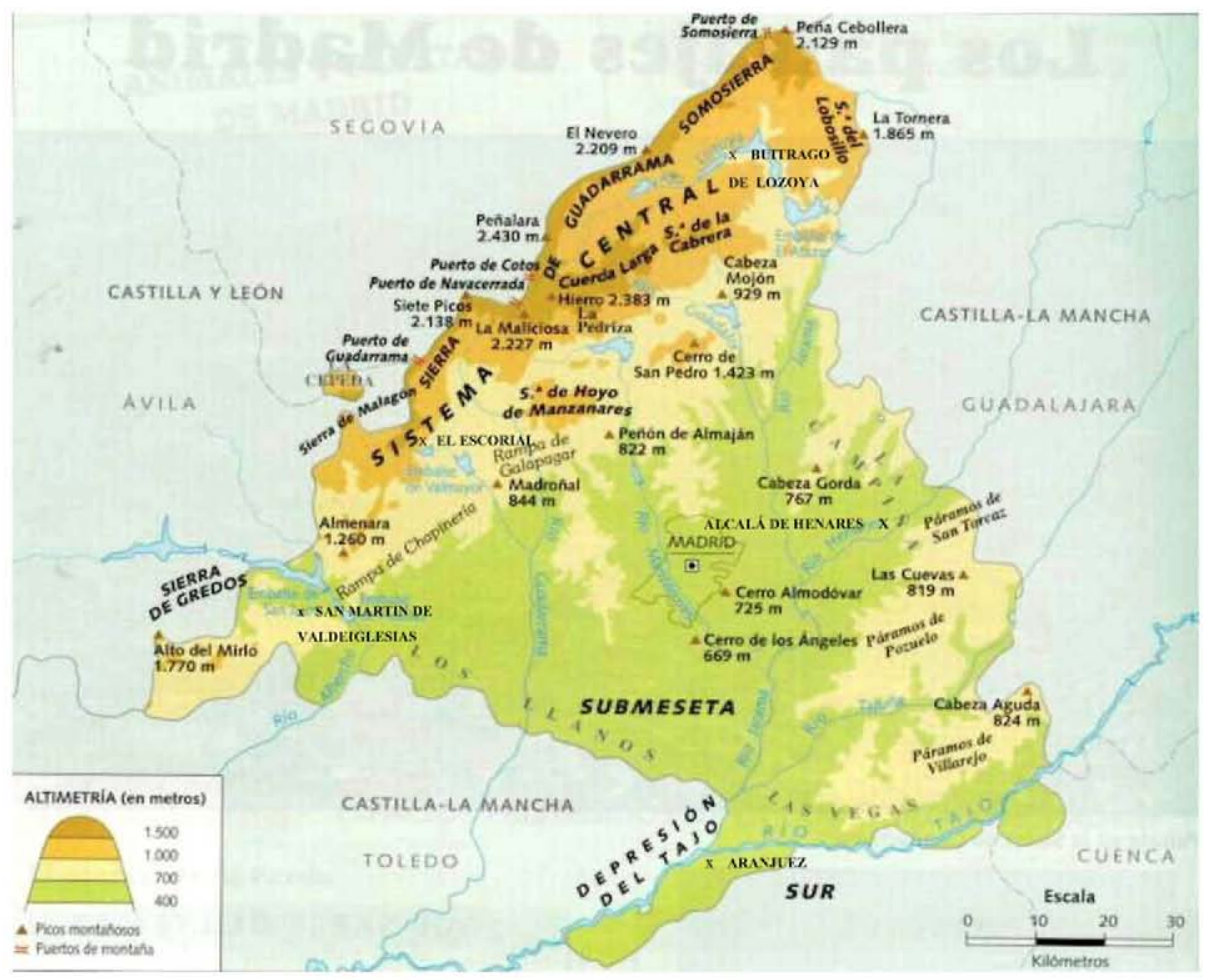

Fig. 1 Altitude map of the Province of Madrid: plateau, chain of mountains, valleys

results depended heavily on the single worst attribute of each land, an alternative quality index (QI) was developed based on an additive valuation of an adequate set of attributes. For that purpose, the authors found they had to design different attribute valuation functions (AVF) to obtain for each attribute an attribute quality index (AQI) in a nominal range $(0,1)$. The AQI values were then weighted and added to obtain a QI expressing the influence of all the attributes. The new QI provides broader information that may prudently be taken as complementary to the SQ classification, as sometimes a single bad attribute produces a serious limitation for a land. Then, to incorporate both aspects in a single value representing the aptitude of use of these types of soils, an original combined land-quality index (CQI) was designed, starting from the QI and correcting it with limits inspired by the SQ index, partially borrowing a fuzzy-set format initially inspired by the ELECTRE TRI classification. An early description of the proposed QI method was presented in poster form (Grau et al. 2006) by some of the authors at the 18th World Congress of Soil Science (July 9-15, 2006, Philadelphia, USA) and attracted attention.

\section{Case-study in the $\mathrm{CM}$ and $\mathrm{SQ}$ classes}

\subsection{The region of Madrid and the CM study}

The Province of Madrid contains at its centre the Metropolitan area of the capital of Spain Madrid (historically Villa de Madrid-Fig. 1), and is legally autonomous as "Comunidad 
Autonómica de Madrid"; the abbreviation (CM) will henceforth be used for the area and for the administration of the area. At a latitude of approximately $40^{\circ} \mathrm{N}$, it is located in the centre of the Iberian Peninsula, in the South-West of Europe, and covers an area of $7995 \mathrm{~km}^{2}$. It consists of two mayor landforms: part of the Iberian plateau consisting of sediments (clays with parts of sand and sometimes other variations, even with gypsum somewhere at its southeast), at an elevation of about $600 \mathrm{~m}$, and to the North, a mountain range formed from primary era granite raised in Tertiary that is part of the Cordillera Central barrier, which runs from East to West and has elevations rising to $1500-2200 \mathrm{~m}$ and many interior valleys. The metropolitan area is very active, especially in services and also in industry, and is a main centre for communications. The whole CM had about 6.45 millions habitants in 2010, a population that had significantly increased in the precedent decade, partly due to immigration. The Province is surrounded by two "autonomies of Castilla", historical regions that are much larger and have with much lower population density. Figure 1 shows an altitude map of $\mathrm{CM}$ with geographic information.

Rainfall varies widely from year to year, with means of $400-460 \mathrm{~mm}$ in the plains and $1100-1300 \mathrm{~mm}$ in the mountains. Water from mountain watersheds is stored in reservoirs for the metropolis, and hence the plains are rather arid and receive little irrigation. Madrid's climate is of Mediterranean latitude and rather continental, receiving irregular winds from west, north or south, partially protected from north squalls by mountains, with a mean annual temperature ranging from 9 to $15^{\circ} \mathrm{C}$, although the mountains are cooler and hence less suitable for many crops. The rivers run mainly from North to South across wide valleys with fertile terraces, joining the westward-flowing Tagus River at the South (Tajo in Spanish).

Land use is diverse. The mountains have original pine and beech forests, while holm oak grows in the sandy-clay soils on the plateau. Several natural areas are protected in the mountains and all along the Manzanares river; some of them allow recreational use. Wheat and fruits are grown in the Southwest and Southeast, and some areas that have traditionally been farmed, such as the Henares River valley (partly irrigated), have been largely taken over for industrial purposes. Irrigation farming is still highly productive in the Tagus valley, at a slightly lower elevation.

Hence, the CM has a variety of lands, with different levels of rainfall and temperature. There is modest agricultural activity including cattle, and parts of the lands are used for urbanisation purposes, transport or services. The CM authority commissioned the CM study (Gallardo et al. 2005), performed by members of the ETS de Ingenieros Agrónomos of UPM (School of Agronomical Engineers of Madrid, or ETSIA of UPM), with the goal of assessing the agro-ecological quality of lands to allow regional planning to conserve the best of them for agriculture. The quality or aptitude of soils for urbanisation purposes is of different nature and will not be considered in this paper, noting only that the metropolis has been and still is expanding. The sources of information were the general expertise of the Soil Science authors of the CM study and a campaign of several years to collect data records from approximately 4000 transects of the soils of the region.

Based on that information, they classified the lands of CM into 122 types, each with a meaningful short name or description, indexed by $i \in(0,121)$. They established sets of $j$ attributes for the types of lands and assigned them values, numerical or categorical, derived from data in the sample records. Tables of data for qualification were archived in matrix forms $\left(x_{i j}\right)$ in MS EXCEL files. The data for the present paper were taken from these tables, with a reduced list of attributes for the QI and CQI qualifications.

That SQ classification, (Gallardo et al. 2005), is a document adopted by the CM authority and used for planning, i.e., to decide if some areas should be reserved for agricultural use. 


\subsection{The SQ classification}

In the CM study (Gallardo et al. 2005) includes information about lands, soils and climate, and defines the land capability of the lands of the CM in a scale of 1:50000 with an SQ classification, and was mainly intended for the land planning services of the CM. That scale was adequate for the land-planning services of the CM, the study's main purpose, and the maps represent the surface with defined areas for the $122 i$-types of lands. The methodology of this SQ work, described also in Gallardo et al. (2002a) and better in Gallardo et al. (2002b), is an adaptation of the systems of Klingebiel and Montgomery (1961) and of Riquier et al. (1970).

The SQ land classification is drawn from the model adapted by the Ministerio de Agricultura (1974) of Spain and by Sánchez et al. (1984), following the modified version by Azevedo and Cardoso (1962) and the second modified version in Ocio et al. (1987), and further combined with the principles of FAO (1976) by Aguilar and Ortíz (1992). These studies in general do not consider contaminants in the region, such as heavy metals, although human uses have produced residues and sometimes garbage in certain local, limited and identifiable sectors that are not considered in these global studies. The SQ classification was effected through a system of land capability that assigns an agro-ecological class to a type of land if a limiting minimum requirement is fulfilled for each $j$-attribute, the class being defined in general by a single worst attribute. The selection of $j$-attributes is specific to these goals. That $\mathrm{CM}$ study also used the cartographic methods indicated in Land System Approach (Gunn et al. 1988). The system focuses on the use of a land that will be sustainable in the medium or long term, identifying for each land a land class labelled from I to VIII. Land class I corresponds to lands with optimal properties that can be used for almost any crops and also for cattle, forest or natural vegetation or leisure purposes. Lands with indexes II-III-IV have growing limitations, with fewer possible crops or the need for more complex techniques. Lands with indexes V to VIII are in principle not suitable for agriculture, with some exceptions for indexes V-VI. The study considered $122 i$-types of lands, with data for a set of 21 integrated properties or $j$-attributes: mean annual precipitation, length of vegetative period, summer mean temperature, winter mean temperature, USLE-C for tolerable soil losses, actual erosion index, soil sealing and crusting risk (SCR), drainage, flooding, soil water storage, effective depth, compaction, permeability, $\mathrm{pH}$, organic matter, CEC (Cation Exchange Capability) in ( $\mathrm{cmol}_{\mathrm{c}} \mathrm{kg}^{-1}$ ), electric conductivity (saturated) or "ECs $\left(\mathrm{dS} \mathrm{m}^{-1}\right)$ ", ESP (Exchange Sodium Percentage), rock fragments in surface horizon, stoniness and general slope. A summary of the requirements for SQ classification is presented in Table 1. In addition to the $S Q$, the authors gave a subindex to the main class, indicating the type of restrictions affecting the land (Gallardo et al. 2002b). These studies were the result of the long-term expertise of the Soil Science team of the "Dto. de Edafología" or Dpt. of Soil Science at ETSIA of UPM, which produced vast archives of structured data and conclusions.

In SS, the expression "Soil Quality" has various other detailed meanings that are not applicable here, e.g., considering how soil quality varies with the history of preceding crops, use of fertilizers, efforts to ameliorate soils, degradation of soils, etc....

\subsection{Soil Science in relation with OR techniques}

Information acquired partly from literature and partly from international Soil Science colleagues about the use of Decision Science (DS) and related OR (Operations Research) in SS will be summarised here. In the rather experimental field of Soil Science, specialists are interested in evaluating soil quality in light of several goals, mainly related to agricultural 
Table 1 Minimum requirements for SQ classification from the CM study data table

\begin{tabular}{|c|c|c|c|c|c|c|c|c|c|}
\hline \multirow[t]{2}{*}{ Attribute } & \multirow[t]{2}{*}{ Optimum } & \multicolumn{8}{|c|}{ Soil Quality Class $S Q, k$} \\
\hline & & $\mathrm{I}, 1$ & II, 2 & III, 3 & IV, 4 & $\mathrm{~V}, 5$ & VI, 6 & VII, 7 & VIII, 8 \\
\hline mean annual precipitation (mm) & 900 & $>700$ & $>550$ & $>400$ & $>300$ & $>300$ & $>300$ & & \\
\hline vegetative period V (months) & 12 & $\geq 9.5$ & $\geq 7.5$ & $\geq 5.5$ & $\geq 3.5$ & $\geq 3.5$ & $\geq 3.5$ & & \\
\hline mean summer temperature & 25 & $>22$ & $>19$ & $>16$ & $>13$ & $>13$ & $>13$ & & \\
\hline mean winter temperature & 9 & $>8$ & & & & & & & \\
\hline USLE-C tolerable soil loss index & 1 & $>0.5$ & $>0.4$ & $>0.2$ & $>0.2$ & $>0.04$ & $>0.04$ & & \\
\hline actual erosion (no, low, much, s) & $\mathrm{n}$ & $\mathrm{n}$ & $\mathrm{nl}$ & $\mathrm{nlm}$ & $\mathrm{nlms}$ & Nlms & nlms & & \\
\hline soil sealing and crusting risk & 1,3 & $<1.6$ & $<2.0$ & $\geq 2.0$ & $\geq 2.0$ & & & & \\
\hline drainage, (excessive, somehow-“, good, poor) & $\mathrm{Gd}$ & Ex.shE.Gd & idem & $\&$ moGd & idem & $\& \operatorname{sh} P$ & idem & $\&$ Po & \\
\hline flooding (none, exceptional, occurring) & $\mathrm{N}$ & $\mathrm{NE}$ & $\mathrm{NEO}$ & $\mathrm{NEO}$ & & & & & \\
\hline soil water storage & $>150$ & $>100$ & $>50$ & & & & & & \\
\hline effective depth & $>100$ & $>75$ & $>50$ & $>25$ & $>25$ & $>25$ & & & \\
\hline Compaction (N, RdR, LdR) (develop. Roots) & $\mathbf{N}$ & $\mathrm{N}$ & $\mathrm{RdR}$ & & & & & & \\
\hline permeability (rapid, moderat., low, imperm.) & moR & Ra.moR.Mo & $\& \mathrm{moLw}$ & $\& L w$ & \&vyLw & idem & idem & idem & $\& \operatorname{Imp}$ \\
\hline $\mathrm{pH}$ & 7 & $5.5-7.3$ & $5-8.5$ & $4.5-9.0$ & & & & & \\
\hline organic matter & 3.5 & $>3$ & $>1$ & & & & & & \\
\hline cation exchange capacity (cmol kg-1) & 40.00 & $>20$ & $>10$ & $>5$ & & & & & \\
\hline carbonates $(\%)$ & 5.00 & $<10$ & $<20$ & $<60$ & $\geq 60$ & & & & \\
\hline electrical conductivity ECs (dSm-1) & 1.00 & $<2$ & $<4$ & $<8$ & $<12$ & & & & \\
\hline sodium adsorption ratio ESP (\%) & 0.5 & $<8$ & $<12$ & $<16$ & $\geq 20$ & $<25$ & $<25$ & $<35$ & \\
\hline fragmented rocks $(\%)$ & 0 & $<15$ & $<35$ & $<60$ & $\geq 60$ & & & & \\
\hline Stoniness (\%) & 0 & $<0.01$ & $<0.1$ & $<3$ & $<3$ & $<15$ & $<15$ & & \\
\hline Soil water storage $(\%)$ & 1 & $<2$ & $<6$ & $<12$ & $<18$ & $<20$ & $<30$ & $<30$ & \\
\hline
\end{tabular}

"idem" means the same as in the box of the left, \& means better are included irrigated lands were considered good for precipitation and water storage 
production, forestry and environment (Dent and Young 1981). The study of soils often varies depending on goals; some attributes are more important in wet areas and others in dry areas. For the present paper, the goal of the valuation has been a sustained agronomic use of the lands, but other studies consider other functions of a soil or land such as sustaining biological activity, regulating water, receiving external materials, storing and cycling nutrients or providing support for human structures, as can be seen in more detail in Allan et al. (1995) in relation to the US Department of Agriculture's Natural Resources Conservation Service. In the literature, there are various cases using diverse methods of OR or of DS for rural or territory planning that include SS considerations, such as Schipper and Sparling (2000), De Pauw and Zoebisch (2002), Gregorich (2002) and Moraes et al. (2002), which reviewed soil condition indicators, and in Zornoza et al. (2006), which studied soil-quality indexes for forest soils under semiarid-dry Mediterranean conditions, using multiple linear regression (MLR) techniques to integrate the pertinent physical, chemical and biochemical properties. Other examples include multi-criteria optimisations with Compromise Programming (CP) models, which Strager and Rosenberger (2007) used to prioritise lands in an action plan and which Krcmar et al. (2005) used for forest and marginal farming land to seek a compromise "on economic, carbon and structural diversity". Chang et al. (1999) also included grey programming (GP) techniques for watershed land-use planning in Taiwan, and Koo and O'Connell (2005) used CP to address the problems surrounding the nitrate pollution of rivers in South-Eastern England. Among general surveys on multiple criteria, let us refer to Figueira et al. (2005), and about OR for natural resources, let us refer to Weintraub et al. (2007). General schemes for evaluating soil using additive indexes were presented by Susan S. Andrews in conference papers concerning wide USDA (United States Department of Agriculture) areas. In fact, there is continual publication in journals on the application of various aspects of $\mathrm{OR}$ in studies of extended land uses and regional planning.

\section{Additive methodology for obtaining a quality index QI}

\subsection{Form of the additive formula and relations with OR}

The authors of this paper relying on the CM study wanted a complementary Quality Index to bring together the influence of different properties of a land. An additive weighted qualification formula was tried, of a form inspired in part from a Compromise Programming (CP) (see Yu 1973; Zeleny 1973; Romero 1993) schema with exponent 1, basically:

$$
q_{i}=\sum_{j=1}^{n} w_{j} \cdot f_{j}\left(x_{i j}\right) \equiv \sum_{j=1}^{n} w_{j} \cdot y_{i j}
$$

In that formula, a quality index (QI) $q_{i}$ is obtained for each type of land $i$ from attribute data values (ADV) $x_{i j}$, often put as $x_{i, j}$ to avoid confusion. To incorporate Soil Science expertise, the authors found it indispensable to design and use, for each attribute $j$ of a list or set $\mathbf{T}$ of $n$ case- $j$-attributes, an "utility-like" attribute valuation function (AVF) $y_{i j}=f_{j}\left(x_{i j}\right)$ to obtain attribute quality indexes (AQI) $y_{i j}$ in a nominal range $(0,1)$, of "more is better" type, i.e. where large values are better. Each $w_{j}$ is a normalised positive weight corresponding to attribute $j$. Let us elicit positive weights $W_{j}$ depending on the importance attached to attribute $j$ in set $\mathbf{T}$, and let us normalise them by $w_{j}=W_{j} / \sum_{j^{\prime}=1}^{n} W_{j^{\prime}}$ so that $\sum_{j=1}^{n} w_{j}=1$. The weights must be elicited by experts in Decision Theory, considering SS goals, after selecting the set $\mathrm{T}$ of $j$-attributes. The $\mathrm{CM}$ region is highly varied and not very important 
in agriculture, and other clearly objective valuations used to compare weights, e.g. with the price or production values of lands, are not evident.

The AVF must be defined to produce an adequate influence of each $j$-attribute on the result from the ADV $x_{i j}$. These AVF are necessary because the ADV have many different definitions and units and because they are not clearly of the "more is better" type, some being of "more is worse" type or having an intermediate optimum (e.g., for acidity, pH 7 is better than $\mathrm{pH} 5$ or $\mathrm{pH} 8.3$ ), and because the influence on quality of the measured value on quality is specific and far from linear. The authors, some of whom had previously published a very different additive OR method for Financial Analysis (Anton et al. 2007a) with other more primitive AVF, have designed a system of AVF described in formulae in the Appendix section 6 and graphed in Figs. 9, 10, 11. These AVF were derived from SS expertise available in the CM study and in books for teaching SS in ETSIA of UPM at undergraduate level (Gallardo et al. 2002a, 2002b) that follow international SS praxis and theories.

After case-study trials including the comparison of results between QI and SQ methods, some of the $\mathrm{AVF} f_{j}$ were modified to produce get negative $\mathrm{AQI} y_{i j}$ when the corresponding ADV $x_{i j}$ indicated strongly bad quality. That modification improved the QI results for attributes such as "slope" and "stoniness" because very high values of these parameters cause much poorer quality for a land.

Formula (1) is sometimes known in OR as a "value function" model, as defined in the overview "Multicriteria decision aid in classification problems" (Zopounidis and Doumpos 2004). In this reference multi-criteria classifications obtained by aggregating the characteristics of the alternatives are addressed in three groups of "forms" proposed for developing decision models: relational forms, value functions and rule-based models. According to these authors, "Due to their simplicity linear or additive functions are usually considered ...these (value function models) provide a simple evaluation mechanism which is easy to understand and implement, ..., (loosing on the ability to capture the interactions between the criteria)". Regarding the third group they say that rule-based "if then else" models can incorporate experience if adequate rules are incorporated. In theory, that approach would lead to rough set theory (Greco et al. 1999, 2001; Figueira et al. 2005) using forms to incorporate SS expertise, but that option becomes at present too complex for the authors. Regarding the first group, Zopounidis and Doumpos $(2004,2002)$ cite as examples of relational forms ELECTRE TRI (Roy and Bouyssou 1993; Roy and Figueira 2002), PROAFTN (Belacel 2000), PAIRCLAS (Doumpos and Zoupounidis 2004), and PROMETHEE TRI (Figueira et al. 2004a, 2004b). The SQ classification may correspond to this form in a much simplified way, because the assessed class is the worst of the classes assigned for each attribute.

In the case study, the authors found that some very few attribute data were missing in the initial matrix data $\left(x_{i, j}\right)$. They used missing indexes (MX) $M X_{i j}$ with value 0 when the ADV data $x_{i j}$ was known and 1 when it is was missing, and replaced (1) with (2) obtained with the same AVFs $y_{i j}=f_{j}\left(x_{i j}\right)$,

$$
q_{i}=\frac{\sum_{j=1}^{n} w_{j} \cdot\left(1-M X_{i j}\right) \cdot y_{i j}}{\sum_{j=1}^{n} w_{j} \cdot\left(1-M X_{i j}\right)} .
$$

\subsection{Application for the Community of Madrid case study}

Starting with the $122 i$-types of land and with the correspondent data from the CM study the authors pursued the application of an additive format, as in (1) or (2). The SQ classes were taken as (I, II, ..., IX) from Gallardo et al. (2005) from best to worst and are indicated by SQ class indexes $k=(1,2, \ldots, 9)$ in the following text. First a set $\mathrm{T}$ of $n=13 j$-attributes 
Table 2 Attributes selected and weights for the QI method

\begin{tabular}{llll}
\hline Attribute & Code $j$ & Weight $W_{j}$ & Normalised weight $w_{j}$ \\
\hline Mean annual precipitation, mm & 1 & 9 & 0.097 \\
Vegetative period, months per year & 2 & 8 & 0.086 \\
USLE-C, tolerable soil losses & 3 & 7 & 0.076 \\
General slope & 4 & 9 & 0.097 \\
Actual erosion index & 5 & 7 & 0.076 \\
Drainage & 6 & 6.5 & 0.07 \\
Permeability & 7 & 5 & 0.054 \\
Stoniness & 8 & 5 & 0.054 \\
Soil sealing \& crusting risk & 9 & 5 & 0.054 \\
pH & 10 & 8 & 0.086 \\
CaCO & carbonates & 6 & 0.065 \\
Effective depth & 12 & 8 & 0.086 \\
CEC, cation exchange capacity & 13 & 9 & 0.097 \\
\hline
\end{tabular}

was defined, extracting these attributes from the 22 ones in CM study (Gallardo et al. 2005; see also Gallardo et al. 2002b), listed in Sect. 2.2. The thirteen were chosen as being rather independent of one another and giving the best indications of quality. Some statistical analysis of the large data tables on these lands from CM study was done with STATGRAPHICS, obtaining Correlation Matrixes with sets of 9 to 25 attributes, and also using Principal Components Analysis also. These analysis helped authors to identify some of the of the attributes as less important or/and dependant on others, but decision on attribute inclusion was mostly based on SS expertise on the CM region.

The elicitation of the weights used in the additive form (1) for the case study was performed by the authors. In general the attributes were sufficiently independent, except for drainage and permeability. The drainage depends heavily on the permeability, but it also depends on local slopes and other factors. In the end, they were both used with restrained pre-standardised weights, 6.5 for drainage and 5 for permeability. The list of the 13 attributes and weights is presented in Table 2. They have their usual SS definitions, which are the same as those in the CM study. The precise description for the case study of each of these QI $j$-attributes, of how the data were put in matrix $\left(x_{i j}\right)$, and the definitions of the corresponding AVFs are presented in the Appendix, which also contains details of the construction of $j$-thresholds to be called $U$ and $V$ for the following CQI method presented in Sect. 4.

These $x_{i j}$ data and forms were introduced from an MS EXCEL file of the CM study in a MATHCAD8_Professional sheet elaborated by the authors to evaluate by (2) the "more is better" QI values $q_{i}$ in nominal range $(0,1)$, for $i=(0,1,2, \ldots, 121)$, as in CM study. These QI values are represented graphically in Fig. 2. The calculation sheet used provides, with minor changes, a variety of intermediate or final calculations. It can produce graphics or tables almost interactively and export results to EXCEL sheets. It was used to adjust the QI method and especially the AVF for the CM case-study, and using its last version (November 2007, slightly adjusted for the drainage attribute), Fig. 3 indicates the QI classes for each SQ class obtained by both QI and SQ methods, showing a valid negative coefficient of correlation -.83 between them and a large range of QI for each SQ. The authors believe that the two methods may be considered complementary, as the traditional SQ depends on a 


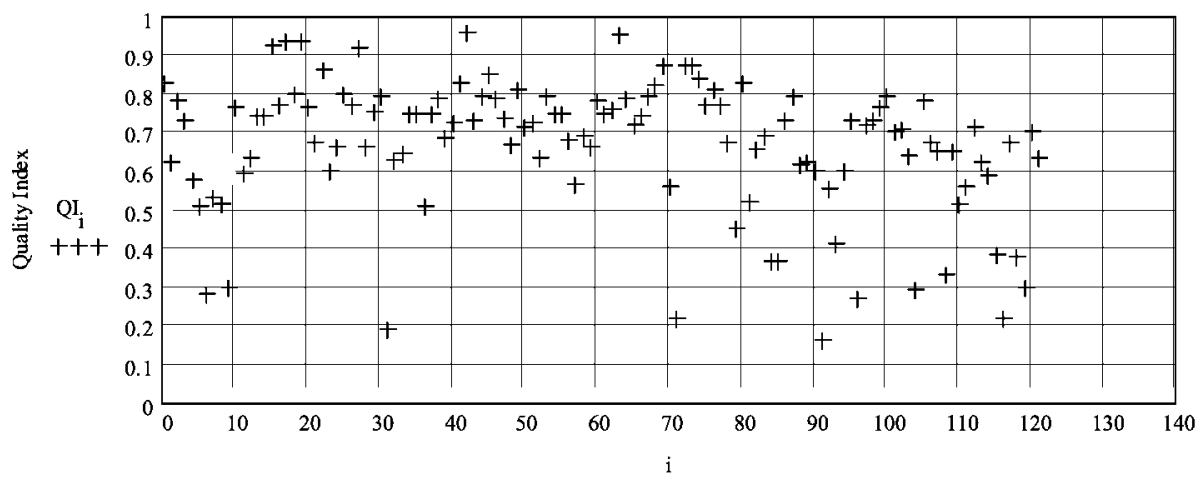

Index $i$ of each type of land

Fig. 2 Quality Indexes $q_{i}$ for the CM case study

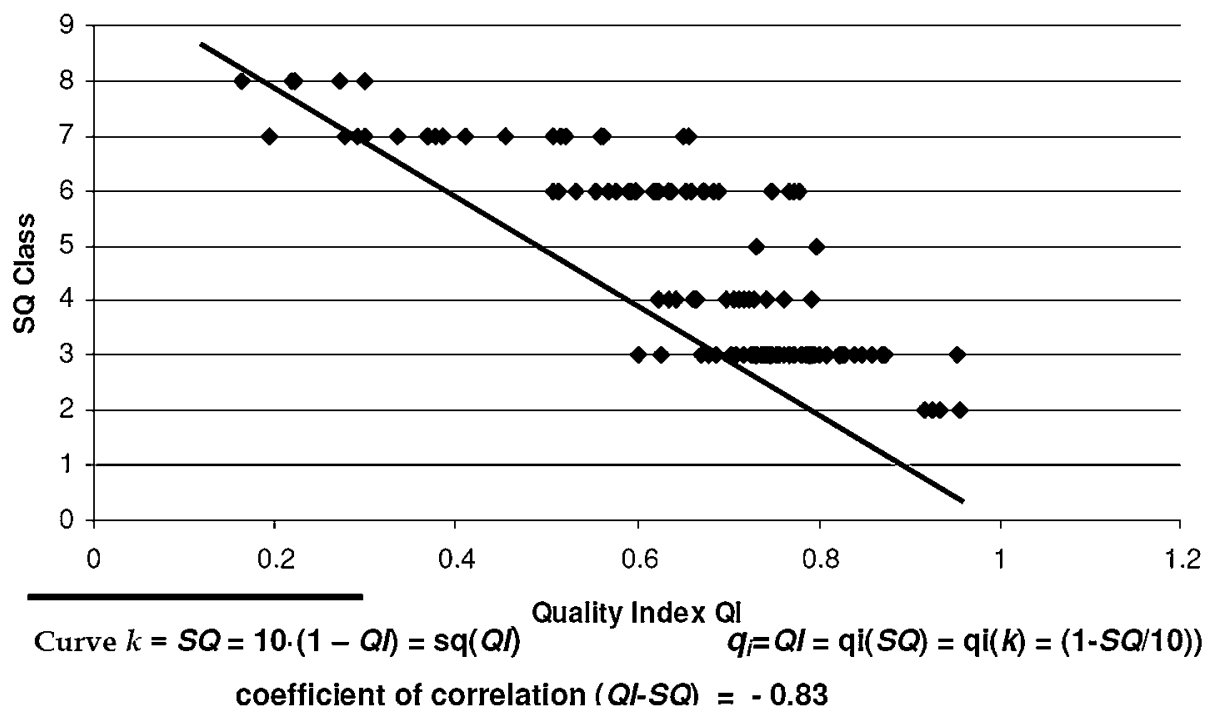

Fig. 3 Quality Indexes $q_{i}$ for each SQ class $k$ in the CM case study

single worst attribute without considering the levels of the others, whereas the QI adds the valuation of a comprehensive set of attributes. For a given type of soil $i$ it is possible to draw an AQI diagram, as in Fig. 4, to see at a glance what QI attributes contribute to good or bad quality.

The precedent method was discussed by some SS experts, including the editors of a special issue of Vadose Zone Journal, who gave criticism and helped authors to find references about OR for SS. They found the AVFs original and observed that the system of functions and qualifications would be different when considering the lands of a large area with very different geology and climate; e.g. in USA the quality of soils in New Mexico and in Ohio will probably depend on different attributes sets, in part because the latitude and climate are different. 


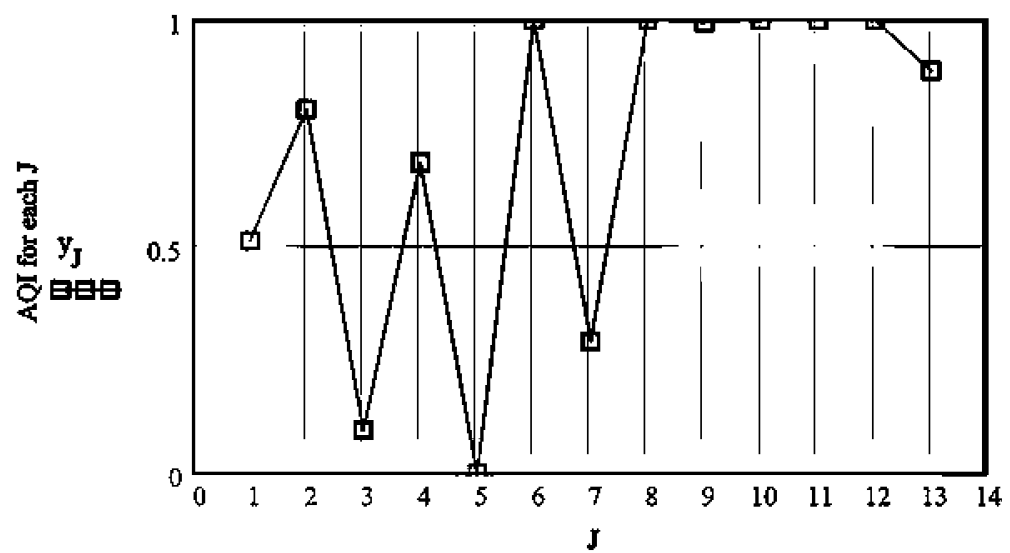

Fig. 4 The $13 J$-attributes AQI values $y_{J}$ for the type of land with $i=83$

\section{Combined methodology for obtaining a CQI}

As stated above, the QI method is presented as complementary to the SQ method. It provides information from 13 attributes, and it might somehow happen that a single extreme ADV $x_{i j}$ indicates a real and strong limitation of quality not enough referred in the corresponding QI value. Now, to produce a single CQI value as a synthesis of both methods, let us start from the previous QI value $q_{i}$ of each $i$-type-of-land and lower it to a CQI value to include the limitations for the SQ. We will use a procedure that has been schematically advanced at the ORAFM in the EURO2007 in Prague (July 8-11) and that can be found as an extended abstract in Anton et al. (2007b).

As in this abstract, the SQ classes $k$ have to be put in the same form as the QI indexes $q_{i}$. With the calibrations and compromises accepted for the case study, near-minimum QI index $Q I=q_{i}^{\prime}$ was adopted for each $k$ as the straight "curve" represented in Fig. 3:

$$
Q I=q_{i}^{\prime}=q i(k)=q i(S Q)=(1-S Q / 10)=(1-k / 10)
$$

To obtain an intermediate CQI valuation, for some of these $k$-classes and for some of the $j$-attributes of set T, a starting threshold $U_{j, k}$ and a worse absolute threshold $V_{j, k}$ were defined for the ADV $x_{i j}$, to be used in a "fuzzy set format" inspired by ELECTRE TRI (Figueira et al. 2004a, 2004b, 2005). A type of land $i$ with a QI value $q_{i}$ better than the $q_{i}^{\prime}=q i(k)$ calculated from its SQ class $k$ will have a CQI value $c q_{i}$ lower than $q_{i}$ and higher or equal than $q_{i}^{\prime}$. For that purpose, a starting value will be $c q_{i}=q_{i}$. Let that $c q_{i}$ be lowered for successive $k$ from 1 to 8 towards a $c q^{\prime}=q i(k+1)$ if for some attribute $j$ the corresponding ADV $x_{i j}$ is worse than $U_{j, k}$, and let it be completely lowered to that $c q^{\prime}=q i(k+1)$ it if it is worse than $V_{j, k}$ for some $j$. To have such a result, a limiting index (LI) $\delta_{i, k, j}$ is defined as going linearly from 0 to 1 as $x_{i j}$ goes from $U_{j, k}$ to $V_{j, k}$, being 0 if $x_{i j}$ is better or equal than $U_{j, k}$ and 1 if it is worse or equal than $V_{j, k}$, getting:

$$
\left\{\begin{array}{l}
\text { Let us have } \delta_{i, k, j}=\left(U_{j, k}-x_{i, k}\right) /\left(U_{j, k}-V_{j, k}\right), \\
\text { if } \delta_{i, k, j}<0 \text { then } \delta_{i, k, j}=0, \\
\text { if } \delta_{i, k, j}>1 \text { then } \delta_{i, k, j}=1
\end{array}\right.
$$


The above is correct if $x_{i j}$ is of the "more is better" type, in which case $U_{j, k}$ must be higher than $V_{j, k}$, and it is also correct in case of the "more is worse" type, in which case $U_{j, k}$ must be lower than $V_{j, k}$. However, for the $\mathrm{pH}$ attribute $(j=10)$, the best value is 7 , and either extreme is bad. Hence, thresholds $U_{10, k}$ to $V_{10, k}$ must be defined for basic soils with $7<U_{10, k}<V_{10, k}$ and thresholds $U_{10, k}^{\prime}$ to $V_{10, k}^{\prime}$ must be defined for acid soils with $7>$ $U_{10, k}^{\prime}>V_{10, k}^{\prime}$. Two LI values $\delta_{i, k, 10}$ and $\delta m_{i, k, 10}$ will be calculated, and for a given soil with a given $x_{i, 10}$, only one of the deltas will be higher than 0 and will be used. It was convenient when programming that the deltas be given the initial value 0 and then changed for the pairs $(k, j)$ for which the thresholds were given appropriate values. For a lower $k$ (for a better class), the thresholds will stricter than for a higher $k$ corresponding to a worse SQ class. If a data item $x_{i j}$ is missing, i.e., if the corresponding MX index $M X_{i j}$ is 1 and not 0 , it would not exceed any limit, and the corresponding $\delta_{i, k, j}$ will receive the value 0 to avoid causing a correction in the following equation (5).

With these $\delta_{i, k, j}$ let us define for each land $i$ and for each class $k$ a "fuzzy set" correcting factor $(\mathrm{CF}) \alpha_{k i} \in(0,1)$, initially set to value 1 and later calculated by (5):

$$
\alpha_{k i}=\prod_{j}\left\{1-\delta_{i k j}\right\}
$$

For the $j=10$, the $\mathrm{pH}$ variable (or for a similar variable in any case study ...), practically the worst of $\delta_{i, k, j}$ and $\delta m_{i, k, j}$ will be introduced. Hence, for a given $k, \alpha_{k i}$ will be 1 if for every attribute $j$ the corresponding $x_{i j}$ are not worse than the thresholds $U_{j, k}$ and $V_{j, k}$ for this $k$. It will be 0 if for at least some $j$ the $x_{i j}$ is worse or equal than the absolute threshold $V_{j, k}$. It will have intermediate values in $(0,1)$ if only some starting thresholds $U_{j, k}$ are violated, which will result in intermediate values for $c q_{i}$.

For effective calculation, the authors first suggested in Anton et al. (2007b) that a given type of land $i$ have its QI $c q_{i}$ lowered towards the value $q i(k+1)$ in a way inspired by ELECTRE TRI if thresholds ( $U$ and $V$ ) exist for a $k$ value and for some $j$-attribute and if such thresholds are violated,

$$
c q_{i}=\operatorname{Min}\left\{\min _{k=1, \ldots, 8}\left\{q_{i} \cdot \alpha_{k i}+q i(k+1) \cdot\left(1-\alpha_{k i}\right)\right\}, q_{i}\right\}
$$

Later it appeared more convenient to use the improved algorithm (7) instead of (6),

$$
\left\{\begin{array}{l}
u q i=q_{i} \\
\operatorname{For}_{k=1, \ldots, 8}\left\{\operatorname{Inf}\left\{u q i=u q i \cdot \alpha_{k i}+q i(k+1) \cdot\left(1-\alpha_{k i}\right), u q i\right\}\right\} \\
c q_{i}=u q i
\end{array}\right.
$$

That is, the new combined soil $c q_{i}$ for each $i$-soil is at first its $q_{i}$. It is examined for the $k$ classes from best (1) to worst (8) (classes I to VIII, IX), and it is reduced to a lower CQI value $q i(k+1)$, completely if a $V_{j, k}$ threshold is violated for some attribute $j$, because then $\alpha_{k i}=0$ for this $k$. It is corrected partially towards this $q i(k+1)$, by means of the $\delta_{i, k, j}$ and of the $\alpha_{k i}$, if only one or some $U_{j, k}$ are trespassed.

The thresholds were adjusted for the case study using the SS expertise from Table 1, and it appeared convenient to give thresholds only for some pairs $(k, j)$, as shown in the table. That property is indicated for the calculation algorithm with indexes $I c_{k, j}$ and $I c_{k, j}^{\prime}$. They are initially 0 , and then $I c_{k, j}$ is changed to 1 if the thresholds $U_{j, k}$ to $V_{j, k}$ are introduced. For $\mathrm{pH}$ attribute with $j=10$ some $I c_{k, 10}^{\prime}$ are changed to 1 to indicate that some $U_{10, k}^{\prime}$ and 
Fig. 5 MATHCAD8PRO algorithm used to calculate the $\mathrm{CQI} \mathrm{cq}$

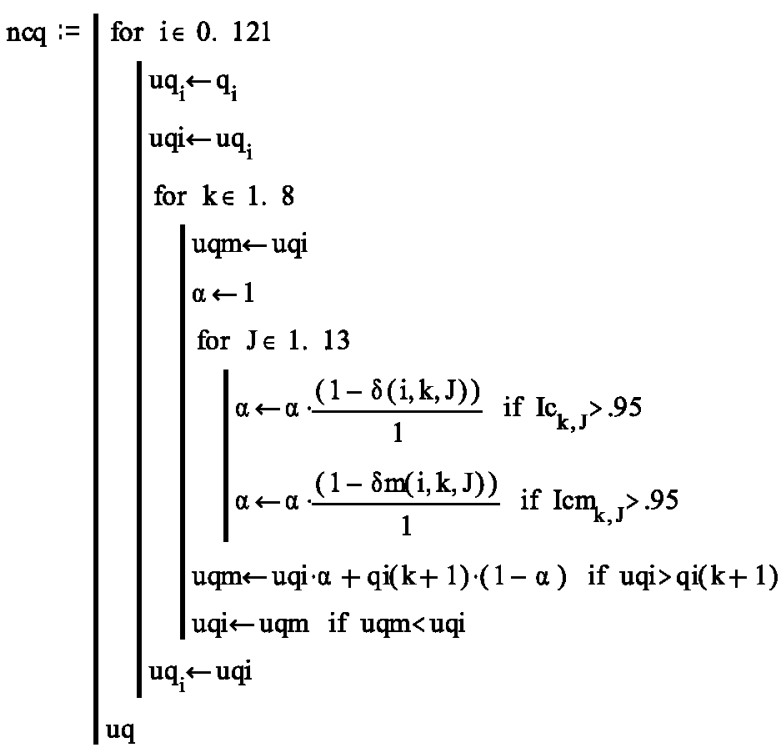

$V_{10, k}^{\prime}$ are given for that $\mathrm{pH}$ attribute. The MATHCAD algorithm used is shown in Fig. 5. It follows (7) and has notation similar to the formulae in the text of the paper, and it has been checked that this algorithm causes, with the gradual thresholds in Tables 3, 4 and 5, a gradual decrease of the value in the case study.

The effect of the threshold values has been checked independently for each $k$-attribute to produce apparently reasonable effects in the values of the $c q_{i}$. It appeared that if a relative threshold $U_{j, k}$ exists for a non-optimal class with a $k$ greater than 1 or 2 , it is better for a lower $k^{\prime}$ to have an absolute threshold equal, $V_{j, k^{\prime}}=U_{j, k}$, or similar, for that $j$. Then the $u q i$ of (7) will already have been lowered when comparing the $x_{i j}$ to the $U_{j, k}$ and $V_{j, k}$ for that $k$.

These precautions were taken for the case study with the choice of thresholds ( $U$ and $V$ ) given in Tables 3, 4 and 5, containing the expertise in SQ classification (Table 1). They need to be in correct order for each $j$, decreasing or increasing with $k$, and in the same order for $U$ and $V(U>V$ or $U<V)$ for a given $(j, k)$. The values of $V$ will be absolute limits corresponding to well-defined SQ criteria or attributes, shown in Table 1 for the case study, causing a decrease of CQI to a lower value. Less rigor is needed for the permissible $U$ values used to produce progressive decreases as the criteria approach limits.

Very few data are missing, and if one of them is for the attribute $j$ of land $i$, the corresponding index $M X_{i j}$ has been previously set to 1 (see end of Sect. 3.1). To prevent inadequate corrections with the algorithm in Fig. 5, the corresponding $\delta_{i, k, j}$ are set to 0 for any $k$ used. In any case missing data might cause an error if the real data would indicate a really bad land. That problem was not encountered in the case study, where very few data were missing.

\section{Application of the CQI method for the CM case study}

With the thresholds in Tables 3,4 and 5, an extended MATHCAD sheet containing the algorithm indicated in Fig. 5 was adjusted to calculate the CQI $c q_{i}$ for all the types of lands in the $\mathrm{CM}$ case study. After some calibration, these CQI results seemed representative. 
Table $3 U_{j, k}$ and $V_{j, k}$ thresholds for $j=1$ to 6

\begin{tabular}{|c|c|c|c|}
\hline \multirow{2}{*}{\multicolumn{2}{|c|}{$\begin{array}{l}\text { 3.a-Mean Annual Precipitation } \\
(\mathrm{mm}) x_{i, 1}\end{array}$}} & \multicolumn{2}{|c|}{ 3.d-Slope $(\%), x_{i, 4}$} \\
\hline & & $U_{4,1}=1$ & $V_{4,1}=8$ \\
\hline$U_{1,1}=700$ & $V_{1,1}=550$ & $U_{4,2}=8$ & $V_{4,2}=14$ \\
\hline$U_{1,2}=550$ & $V_{1,2}=400$ & $U_{4,3}=14$, & $V_{4,3}=24$ \\
\hline$U_{1,3}=400$ & $V_{1,3}=300$ & $U_{4,4}=24$ & $V_{4,4}=28$ \\
\hline$U_{1,5}=300$ & $V_{1,5}=299.8$ & $U_{4,5}=28$ & $V_{4,5}=35$ \\
\hline$U_{1,6}=300$ & $V_{1,6}=250$ & $\begin{array}{l}U_{4,6}=35 \\
U_{4,7}=50\end{array}$ & $\begin{array}{l}V_{4,6}=50 \\
V_{4,7}=100\end{array}$ \\
\hline \multicolumn{2}{|c|}{ 3.b—Vegetative Period (months), } & \multicolumn{2}{|c|}{ 3.e-Actual erosion index, } \\
\hline$x_{i, 2}$ & & $x_{i, 5}$ & \\
\hline$U_{2,1}=9.5$ & $V_{2,1}=7.5$ & $U_{5,1}=0$ & $V_{5,1}=1$ \\
\hline$U_{2,2}=7.5$ & $V_{2,2}=5.5$ & $U_{5,2}=1$ & $V_{5,2}=2$ \\
\hline$U_{2,3}=5.5$ & $V_{2,3}=3.5$ & $U_{5,3}=2$ & $V_{5,3}=3$ \\
\hline$U_{2,5}=3.5$ & $V_{2,5}=3.4998$ & $U_{5,6}=3$ & $V_{5,6}=4$ \\
\hline$U_{2,6}=3.5$ & $V_{2,6}=3$ & & \\
\hline \multicolumn{2}{|c|}{ 3.c-USLE-C index, $x_{i, 3}$} & \multicolumn{2}{|c|}{ 3.f-Drainage, $x_{i, 6}$} \\
\hline$U_{3,1}=0.5$ & $V_{3,1}=0.4$ & $U_{6,2}=4$ & $V_{6,2}=3$ \\
\hline$U_{3,2}=0.4$ & $V_{3,2}=0.2$ & $U_{6,3}=3$ & $V_{6,3}=2.998$ \\
\hline$U_{3,3}=0.2$ & $V_{3,3}=0.1998$ & $U_{6,4}=3$ & $V_{6,4}=2$ \\
\hline$U_{3,4}=0.2$ & $V_{3,4}=0.04$ & $U_{6,5}=2$ & $V_{6,5}=1.998$ \\
\hline$U_{3,5}=0.04$ & $V_{3,5}=0.03998$ & $U_{6,6}=2$ & $V_{6,6}=1$ \\
\hline$U_{3,6}=0.04$ & $V_{3,6}=0.001$ & $U_{6,7}=1$ & $V_{6,7}=0$ \\
\hline
\end{tabular}

They are presented in Fig. 6, with the preceding QI results $q_{i}$ of Fig. 2, showing that the CQI conserve differences in spite of important reductions from the QI values depending on critically bad attributes. The relationship of the CQI to the SQ values is shown in Fig. 7, in which the coefficient of correlation between CQI values and the index $k$ of SQ method was $\{-0.91\}$, closer to -1 than the similar $\{-0.83\}$ between QI values and $k$ shown in Fig. 3. For the CQI values, the $c q_{i}$ results are less than or equal to the QI values $q_{i}$ depending on attributes that limit the quality in the sense of the SQ limits, and as a single number they represent better the agro-ecological quality of the types of lands than the SQ classes. Some of the lands have similar QI and CQI values, $Q I$ and $C Q I$, including the worst ones. Some of the better $q_{i}$ were reduced to lower $c q_{i}$ because the corresponding $i$-soils were not irrigated in an area with about $450 \mathrm{~mm}$ mean yearly rain. As the method is new the new original CQI indices might still be cautiously considered complementary to the official SQ classification. Soil Science is experimental, and the concept of quality depends on the goals for assessment. These indices are a special aid to contribute to the expert knowledge of these soils types.

The case study is done with 122 types of lands with 13 attributes, too much information to be evaluated together. To inspect the procedure, some of the types of lands are revised with the help of their AQI diagrams obtained using the MATHCAD sheet and shown in Fig. 8:

1. In land type $i=111$, (depressions with peat soils/"Toyas con suelos turbosos"-Fig. 8a) the obtained SQ class is VII that correspond to SQ index $k=7$, the QI is $q_{111}=0.56121$, and the CQI is $c q_{111}=0.3$. The difference $q_{111}-c q_{111}$ is exceptionally high, due mostly to "poor drainage" qualification $\left(x_{111,6}=1, V_{6,6}=1\right)$, on which grounds these soils were 
Table $4 U_{j, k}$ and $V_{j, k}$ thresholds for $j=7,8,9,11,12,13$

\begin{tabular}{|c|c|c|c|}
\hline \multicolumn{2}{|c|}{ 4.a-Permeability, $x_{i, 7}$} & \multirow{2}{*}{\multicolumn{2}{|c|}{$\begin{array}{l}\text { 4.d-Carbonates } \\
\left(\% \mathrm{CO}_{3} \mathrm{Ca}\right), x_{i, 11}\end{array}$}} \\
\hline$U_{7,1}=4$ & $V_{7,1}=3$ & & \\
\hline$U_{7,2}=3$ & $V_{7,2}=2$ & $U_{11,1}=10$ & $V_{11,1}=20$ \\
\hline$U_{7,3}=2$ & $V_{7,3}=1$ & $U_{11,2}=20$ & $V_{11,2}=60$ \\
\hline$U_{7,6}=1$ & $V_{7,6}=0.988$ & $U_{11,3}=60$ & $V_{11,3}=65$ \\
\hline$U_{7,7}=1$ & $V_{7,7}=0$ & & \\
\hline \multicolumn{2}{|c|}{ 4.b-Stoniness $(\%), x_{i, 8}$} & \multirow{2}{*}{\multicolumn{2}{|c|}{$\begin{array}{l}\text { 4.e-Effective Depth } \\
(\mathrm{cm}), x_{i, 12}\end{array}$}} \\
\hline$U_{8,1}=0.01$ & $V_{8,1}=0.1$ & & \\
\hline$U_{8,2}=0.1$ & $V_{8,2}=3$ & $U_{12,1}=100$ & $V_{12,1}=75$ \\
\hline$U_{8,3}=3.01$ & $V_{8,3}=3.002$ & $U_{12,2}=75$ & $V_{12,2}=50$ \\
\hline$U_{8,4}=3$ & $V_{8,4}=15$ & $U_{12,3}=50$ & $V_{12,3}=25$ \\
\hline$U_{8,5}=15.1$ & $V_{8,5}=15.02$ & $U_{12,5}=25$ & $V_{12,5}=24.98$ \\
\hline$U_{8,6}=15$ & $V_{8,6}=24$ & $U_{12,6}=25$ & $V_{12,6}=20$ \\
\hline \multirow{2}{*}{\multicolumn{2}{|c|}{$\begin{array}{l}\text { 4.c-Soil sealing and } \\
\text { crusting risk, } x_{i, 9}\end{array}$}} & \multicolumn{2}{|c|}{ 4.f-CEC $\left(\mathrm{cmol} \mathrm{kg}^{-1}\right), x_{i, 13}$} \\
\hline & & $U_{13,1}=20$ & $V_{13,1}=10$ \\
\hline$U_{9,1}=1.6$ & $V_{9,1}=2.0$ & $U_{13,2}=10$ & $V_{13,2}=5$ \\
\hline$U_{9,2}=2.0$ & $V_{9,2}=2.1$ & & \\
\hline$U_{9,3}=2$ & $V_{9,3}=2.5$ & & \\
\hline$U_{9,4}=2.5$ & $V_{9,4}=3$ & & \\
\hline
\end{tabular}

Table $5 U_{j, k}$ and $V_{j, k}$ thresholds for $j=10, \mathrm{pH}$

\begin{tabular}{|c|c|c|}
\hline 5.a-pH, $x_{i, 1}$ & , acid soils side & 5.b-pH, $x_{i, 10}$, basic soils side \\
\hline$U_{10,1}=5.5$, & $V_{10,1}=5$ & $U_{10,1}=7.3, \quad V_{10,1}=8.5$ \\
\hline$U_{10,2}=5$ & $V_{10,2}=4.5$ & $U_{10,2}=8.5$ \\
\hline$U_{10,3}=4.6$ & $V_{10,3}=4.2$ & $U_{10,3}=8.9, \quad V_{10,3}=9.2$ \\
\hline
\end{tabular}

classified as SQ VII $(k=7)$. This type contains peat soils formed on depressions in the foothills surrounding Madrid's mountains, where vegetative period is short (five months) and where precipitation is high $(1300 \mathrm{~mm} / \mathrm{year})$, corresponding to forestry land use. The experts agree that they are rather good only for ash trees, which justifies a rather low qualification. The QI index is higher because many other attributes are good, in spite of negative $y_{111,6}=-1$ for drainage; in fact, the qualifications for drainage for the lands of the $\mathrm{CM}$ case study were high for all other types. These special soils have $\mathrm{pH}=4.8$ and (mean) slope $=3 \%$ and flooding and pooling were nil in records. Thus, in this case, probably the most unfavourable for the present methods, the QI method indicates that many attributes are good, but due to the special case the QI method must be complemented by the SQ or CQI method to indicate the lower quality confirmed by experts.

2. Land type $i=1$ (little hills with terra rossa/"Cerrillos con Terra Rosa"-Fig. 8b) is characterised by an SQ class IV and $k=4$. The calculated QI value $q_{1}=0.62222$ is only slightly superior to the CQI value $c q_{1}=0.61049$, and the three indices are in correspondence. This type of soil occurs in the South-East part of the region at an altitude higher than the nearby Henares valley that has better lands, it is subject to moderate erosion $\left(x_{1,5}=2\right)$, with a basic $\mathrm{pH}=8$, and with reduced depth $(36.8 \mathrm{~cm})$. Rainfall is $450 \mathrm{~mm} /$ year, and the vegetative period is 7 months.

3. In land type $i=63$ (alluvial irrigated plains with non-calcareous fluvisoils / "Llanuras aluviales con regadios con fluvisoles no calcáreos"-Fig. 8c), the obtained values are: 


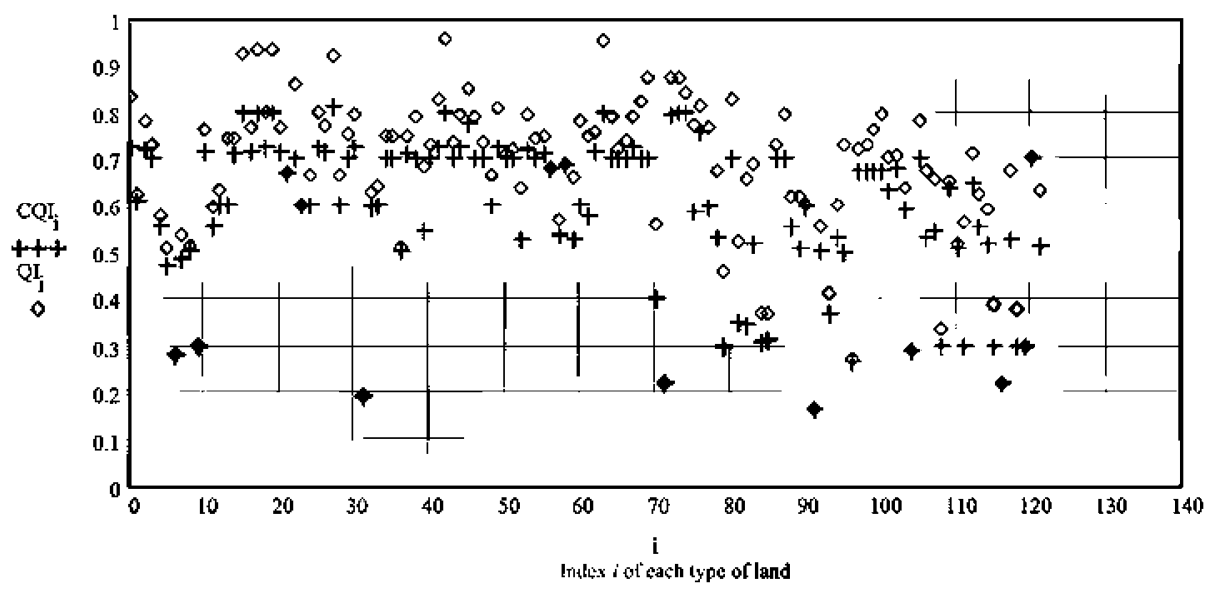

Fig. $6 \mathrm{CQI}$ and QI values for the CM case study

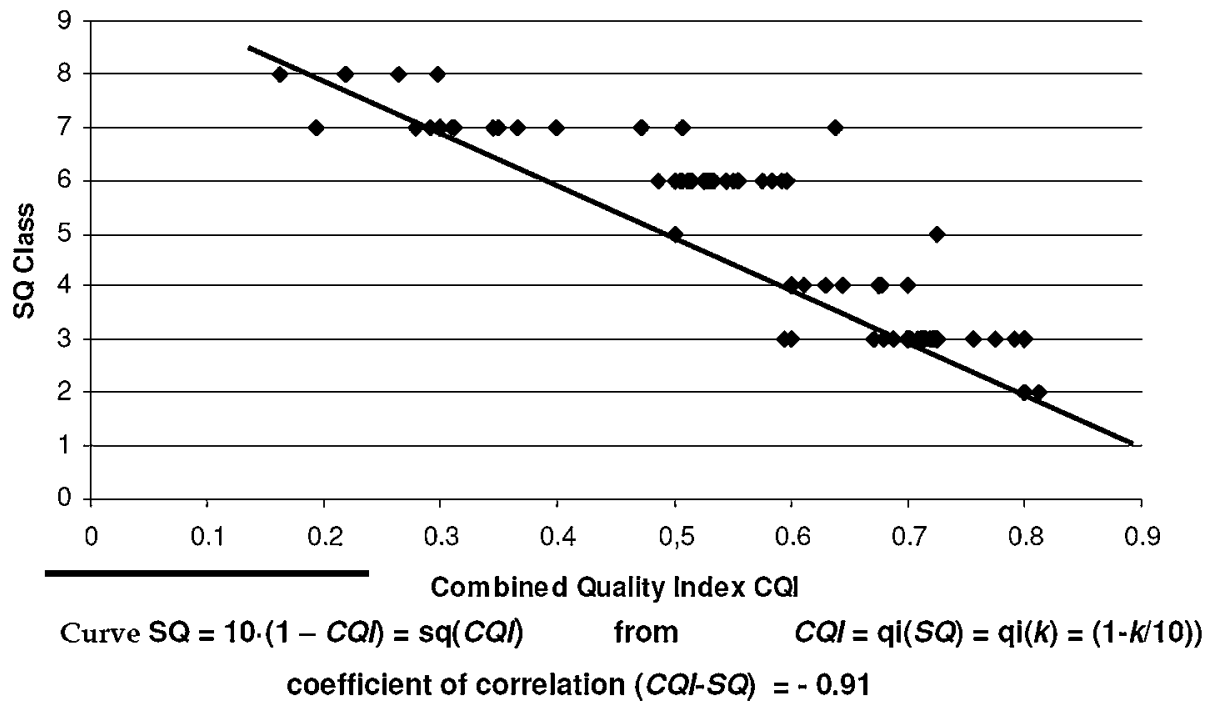

Fig. 7 CQI values $c q_{i}$ for each SQ class $k$ in the CM case study

SQ class $=$ III and $k=3$, QI value $q_{63}=0.9439$. The CQI value $c q_{63}=0.8$ is inferior to QI because of the actual erosion index. The SQ class is only III or $k=3$. This value may be reduced because Precipitation is $450 \mathrm{~mm}$, which has been compensated for in the QI or CQI methods because of irrigation. This type of soil is taken from the southward running Jarama valley. It has low calcium content and is very good for farming.

4. Land type $i=23$ (Loess with calcisoils/"Loes con calcisoles"-Fig. 8d) is characterised by a SQ value III $(k=3)$ and a QI value $q_{23}=0.60158$, very similar to the CQI value $c q_{23}=0.60028$. This type of soil is silt deposits in areas of the South or South-West of CM. The qualification SQ value III is more favourable than the QI or CQI, which is lowered from approximately 0.66 or 0.65 because (see Fig. 8d) of bad Soil Sealing and Crusting Risk (SCR) that resulted in $y_{23,9}=-0.8$ with AVF of Fig. 10c with (16). For 


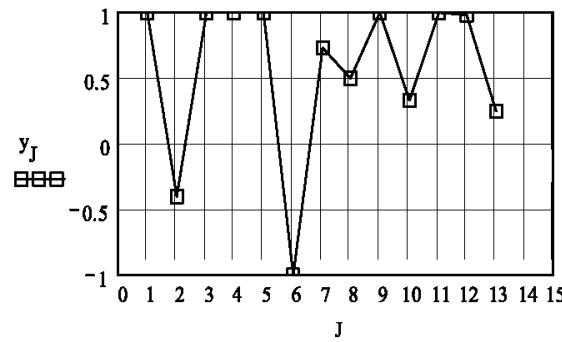

8a $\quad i=111$, Depressions with peat soils

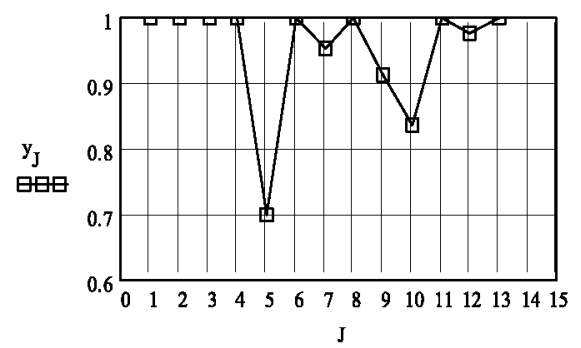

8c $\quad i=63$, Alluvial irrigated plains with not calcareous fluvisoils .

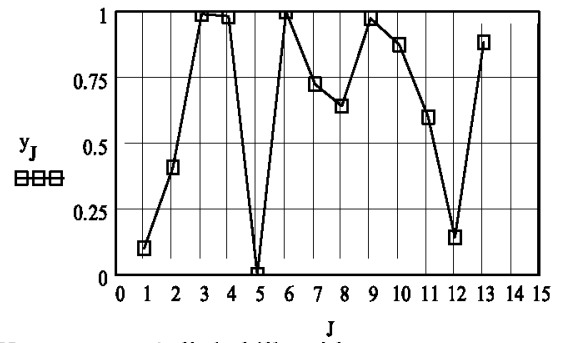

$8 \mathbf{b}$ $i=1$, little hills with terra rosa

9

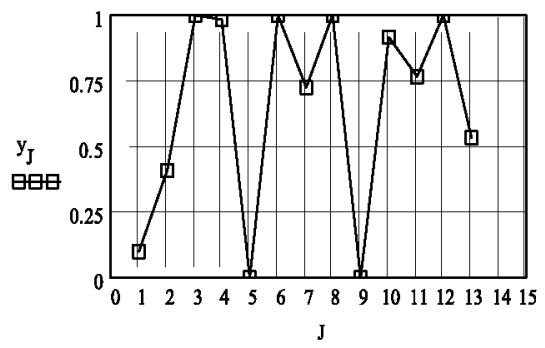

8d $i=23$, Loess with calcisoils, $\left(y_{23,9}=0\right)$

Fig. 8 AQI diagrams for various types of lands of the CM

these soils, some of the SS authors think that a negative value could be excessive for that level of precipitation $(450 \mathrm{~mm} /$ year $)$. Then $q_{23}=c q_{23}=0.66$ could be better and nearer to $S Q=$ III or $k=3$ in Fig 7. As a similar compromise the $y_{23,9}$ was corrected to a value 0 before drawing Fig. 8d, but not elsewhere. In fact CM experts say that such high values of that attribute $(j=9)$ are less of an indication of bad soil because average annual precipitation is only $450 \mathrm{~mm} /$ year. Other foreign experts (from Vadose Zone Journal), perhaps with wetter areas in mind, indicated that they are relatively bad because of their SCR.

Such cases have been considered to adjust the AVF functions and the thresholds specifically for this collection of CM lands. They show that the QI value contains more information than the SQ value, but it is better treated as a complement of that SQ value, which may detect a real limitation of the soil. The new $\mathrm{CQI}$ incorporates these limits to a great extent. These methods can be adapted to other areas and to different goals by selecting the system of data, of $\mathrm{AVF}$ and the thresholds adequate for them.

\section{Conclusions}

This study represents the application of mathematical theory of a weighted additive classification procedure to obtain a QI value for types of soils, and a relational form method inspired in "fuzzy set" ranking methods to obtain a CQI value that takes into account threshold values of properties. The use of these methods is a synthesis from a large body of previous SS studies, concepts and data on the soils of the CM, including the CM Study incorporating a list of land types, attributes, matrices of data, and an SQ classification intended for 
territorial planning. From this CM study, the authors selected a comprehensive subset $\mathrm{T}$ of attributes. For each attribute, effects were measured using AVF obtained from the SS of the $\mathrm{CM}$ study to obtain $\mathrm{AQI}$ values, ranging primarily from zero to one, and accommodating negative numbers for cases in which the attribute was clearly indicative of poor soil quality. The comparison of the QI results to the prior SQ ones showed that this new method is both compatible with and complementary to the SQ approach. The CQI index incorporates both the influence of these valuations and of these effective thresholds.

The case study proved these indices to be an effective tool for distinguishing many soil types and for identifying the variables with the greatest impact on soil quality. The data used and the results (QS, QI, CQI) indicated in the present paper contain usable information on the lands of a region compiled from records too diverse and complicated to be assessed together without these results. Further research would be needed to apply this methodology to other scenarios and goals for evaluation. First, it would be necessary to establish the appropriate sets of soil types and attributes. Second, appropriate matrices of $x_{i, j}$ representative data should be defined. Third, the AVF and the thresholds $\mathrm{U}$ and V must be calibrated if used for regions with different geology or climate, or different agricultural use by a different population.

The CM case study presented here demonstrates the applicability of the method and the level of detail needed in data in order to achieve a meaningful classification.

Acknowledgements The authors thank the researchers who, relying on their deep SS expertise and knowledge on their CM region, conducted the CM survey, compiled the data and attributes and offered them as a guide for this study. Funding was also provided by Spanish Ministerio de Ciencia e Innovación (MICINN) through project no. AGL2010-21501/AGR.

\section{Appendix: Definition of the AVF and of the thresholds for the CM case study}

As stated above, for each one of the 13 attributes chosen in set T for QI and CQI methods, an attribute value function (AVF) $y_{i j}=f_{j}\left(x_{i j}\right)$ has been designed for the CM case study. That design was done by adapting, aided by trial and error procedures, mathematical algorithms in the calculation sheet to obtain auxiliary mathematical formulas and to draw the corresponding curves represented in Figs. 9, 10 and 11. Each AVF is represented in grey and the small black squares represent almost all the attribute values for the 122 land types in the case study, some being superimposed. They conform to the SS definitions of the attribute variables taken from Gallardo et al. (2002a, 2002b), used for the CM study and adapted locally as shown in Table 1 . They yield results $y_{i j}$ in the nominal range from zero to one, which are neither random distribution nor fuzzy set variables, and the values below zero are intended as penalties.

For each attribute, the choice of threshold values $U_{j, k}$ and $V_{j, k}$, complemented by $U_{j, k}^{\prime}$ and $V_{j, k}^{\prime}$ for $j=10$, is given in Tables 3,4 and 5 as copied directly from items in the interior of the calculation sheet used. They are now presented with brief comments for each $j$-attribute on the effect of these threshold limits, indicating how they were adjusted in value and how many of them were taken for each $k$ at best. Those factors were adjusted in trials with limits set for the single attributes, requiring meticulous work by the authors. The limits were inspired by the CM study, Table 1 gives a short summary. This work incorporates the SS expertise about the CM from Gallardo et al. (2002a, 2002b, 2005), which has not been published in English language journals yet. For some $j$, auxiliary values of $U_{j, k}$ and of $V_{j, k}$ were added with care for some $k$ to get the $c q_{i}$ values down more progressively. 


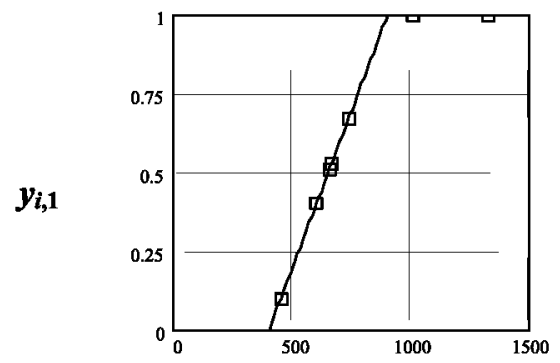

9a

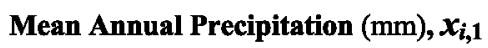

$y_{i, 2}$

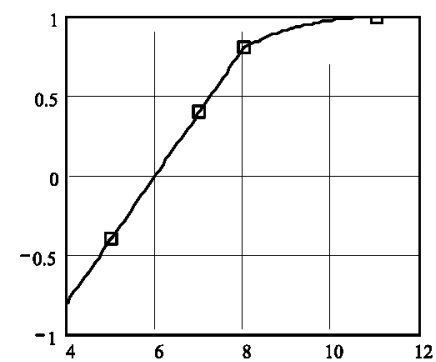

9b

Vegetative Period (months), $x_{i, 2}$

$y_{i, 3}$

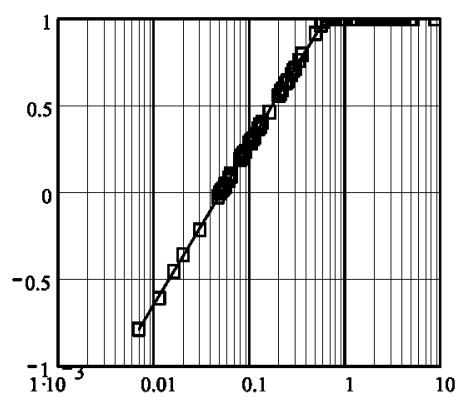

$9 \mathrm{c}$

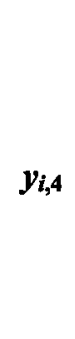

9d

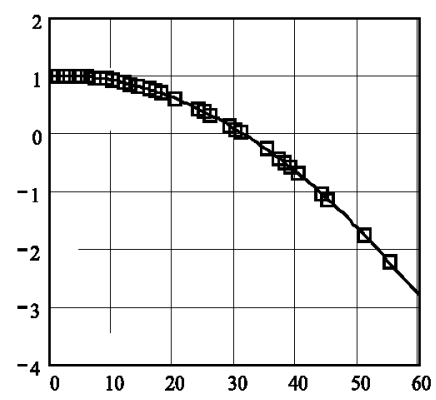

Slope (\%), $\boldsymbol{x}_{i, 4}$

$\boldsymbol{y}_{i, 5}$

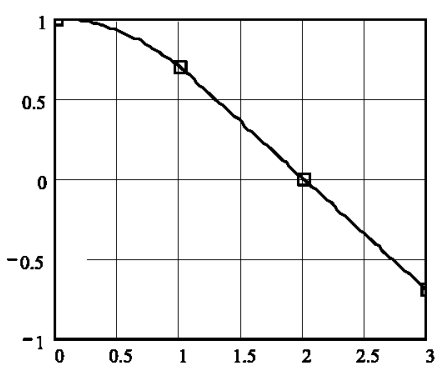

Actual erosion index $\boldsymbol{x}_{i, 5}$

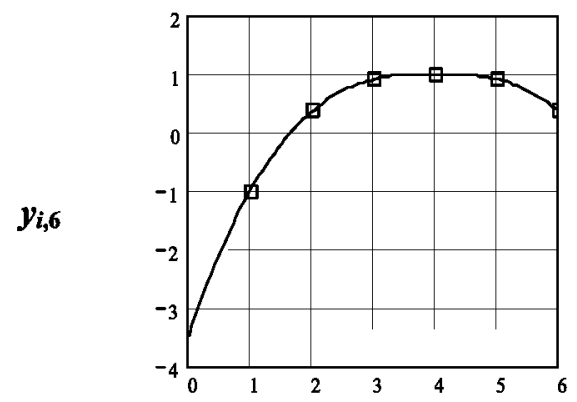

9f

\section{Drainage, $x_{i, 6}$}

Fig. 9 AVF for $j=1$ to 6

1. Mean Annual Precipitation (mm). In Madrid, this $x_{i, 1}$ variable is of the "more is better" type, because the scarcity of water limits agricultural production. The data were converted linearly so that where $x_{i, 1}$ values were low, around $450 \mathrm{~mm}$, which occurs normally in many flat areas of $\mathrm{CM}$ at an elevation of about $650 \mathrm{~m}$, the $y_{i, 1}$ index was barely higher than 0 . Values greater than or equal to $900 \mathrm{~mm}$ were assigned an index of 1 , denoting highly favourable circumstances for the region; higher values up to $1200 \mathrm{~mm}$ or more would be more suitable for subtropical latitudes, where $450 \mathrm{~mm}$ would require a negative $y_{i, 1}$. Some of the land types were from sites with up to $1300 \mathrm{~mm}$ of rainfall but with less favourable 
$y_{i, 7}$

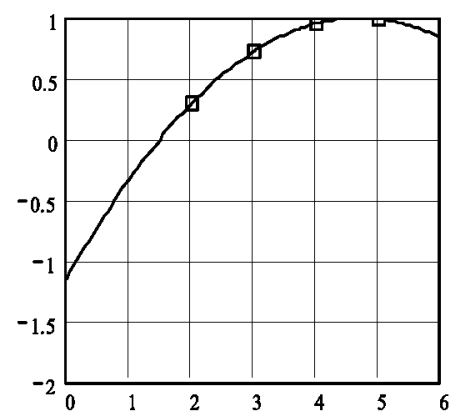

10a

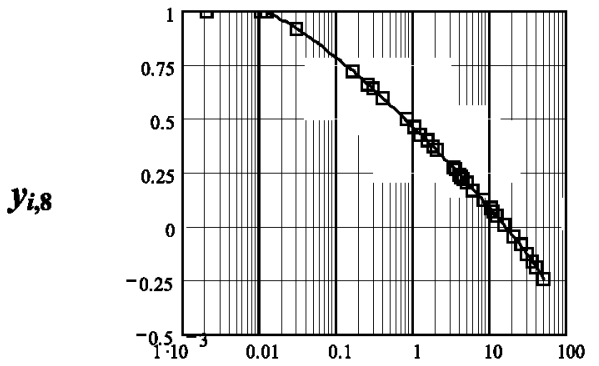

10b

$$
\text { Stoniness (\%), } \boldsymbol{x}_{i, 8}
$$

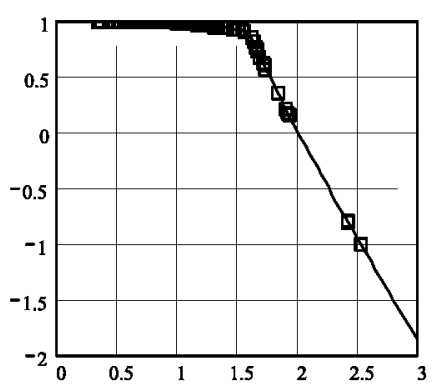

10c Soil sealing and crusting risk, $x_{i, 9}$ $y_{i, 10}$

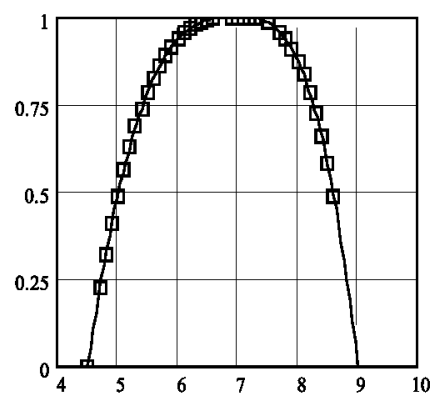

10d

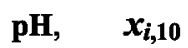

$\boldsymbol{y}_{i, 11}$

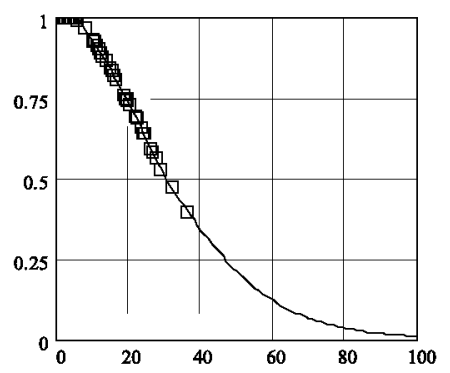

10e Carbonates $\left(\% \mathrm{CO}_{3} \mathrm{Ca}\right), \boldsymbol{x}_{i, 11}$

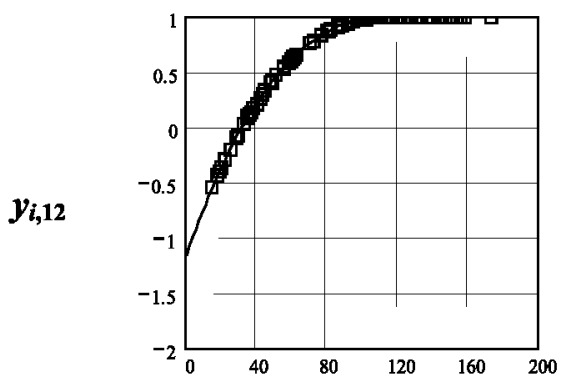

$10 f$

\section{Effective Depth (cm), $\boldsymbol{x}_{i, 12}$}

Fig. 10 AVF for $j=7$ to 12

lower temperatures; and there are no values lower than $450 \mathrm{~mm} / \mathrm{year}$ in the CM region (although they do occur in some special areas of Spain). Such values would require negative $y_{i, 1}$. On those grounds, the AVF function adopted $f_{1}$ and represented in Fig. $9 \mathrm{a}$ is

$$
y_{i, 1}=f_{1}\left(x_{i, 1}\right)= \begin{cases}\frac{x_{i, 1}-400}{900-400} & \text { if } x_{i, 1} \leq 900 \\ 1 & \text { if } x_{i, 1}>900\end{cases}
$$


Fig. 11 AVF for $j=13$

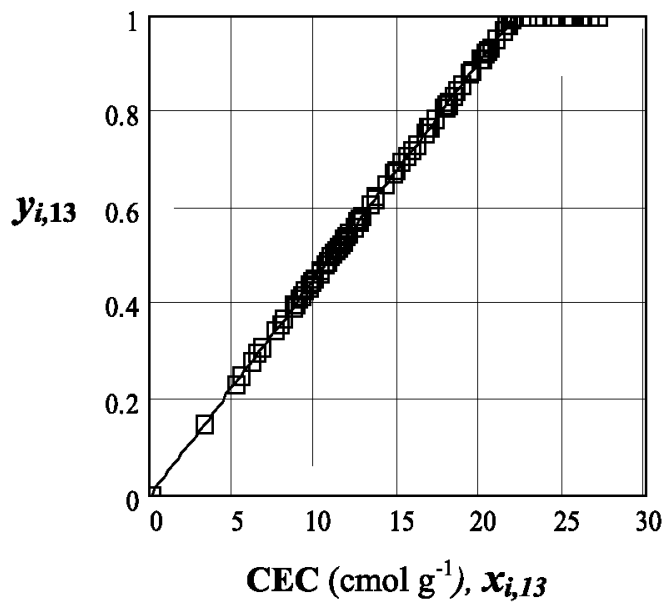

Some types of land are irrigated, and for them, that attribute has been considered to be at its best, the AVF value $y_{i, 1}$ was changed to the best value 1 before entering it in the additive formula (2), and also the $\delta(i, k, 1)$ were considered as 1 before entering in the threshold algorithm of Fig. 5. For the thresholds, the values of $U_{1, k}$ and of $V_{1, k}$ in Table 3.a were taken prudently from the SQ limits of Table 1 . That choice lowers the CQI to near 0.7 if the Precipitation $x_{i, 1}$ is $450 \mathrm{~mm}$, as happens in the main plateau of the CM except for irrigated lands. That value corresponds to the straight curve $S Q=10-10^{*} Q I$ of Figs. 3 and 6 and to the criteria in SQ method of limiting the class as not better that the class III because of limited annual precipitation, e.g. for types of soils ( $i=1,3,10,20)$. Auxiliary values of $U_{1, k}$ and of $V_{1, k}$ have been added for $k=5$ to reduce the $c q_{i}$ to 0.4 if $x_{i, 1}<300$, usable for other quasi-desert regions of Spain; less than 250 is often considered desert.

2. Vegetative Period (months). Variable $x_{i 2}$ is also a "more is better" type measure, ranging from 0 to 12 and meaning "number of humid months in which the mean temperature is greater than or equal to $6.5^{\circ} \mathrm{C}$ " (Driessen and Konijn 1992). For a total of eight months, regarded to be a good result in the conditions prevailing in Madrid, let the $y_{i 2}$ index be 0.8 . Let six months be assigned an index of 0 , and let five months or less, as found in the mountains where the climate is harsher, be penalised with a negative value. The index is 1 near Aranjuez in the lower (and irrigated) Tagus valley. The AVF $\mathrm{f}_{2}$ is linear in $x_{i 2}$ for values smaller than 8 and goes up slowly towards $y_{i 2}=1$ for $x_{i 2}$ values greater than 8 as shown in Fig. $9 \mathrm{~b}$, and in (9)

$$
y_{i 2}=f_{2}\left(x_{i 2}\right)= \begin{cases}0.4 \cdot x_{i 2}-2.4 & \text { if } x_{i 2} \leq 8 \\ 1-0.2 \cdot\left(12-x_{i 2}\right)^{3} \cdot 4^{-3} & \text { if } x_{i 2}>8\end{cases}
$$

The threshold values of $U_{2, k}$ and of $V_{2, k}$ in Table 3.b were also inspired by the SQ limits of Table 1. They have the effect in CM case-study of lowering the CQI to a limit below 0.7 if the Vegetative Period is 5 months, as in flat parts in granitic mountains ( $i=97,98,99,1000,101)$, and of making its value 0.8 for a Vegetative Period of 8 months $(i=72,73,74)$ or near 0.4 if it is 7 months $(i=41,44,46,49)$. In CM areas the vegetative period is not below 5 , and is 5 months only at higher altitude. Auxiliary values of $U_{2, k}$ and of $V_{2, k}$ have been added for $k=5$ so as to reduce the $c q_{i}$ to 0.4 when $x_{i, 2}<3.5$. 
3. USLE-C. This "more is better" type, much SS-elaborated, $x_{i, 3}$ index assesses nonerosive cover and cropping management, determining tolerable soil losses from a combination of different properties. In this study, the values ranged from $7 \cdot 10^{-3}$ to 8.391 . Values of $x_{i, 3}$ greater than or equal to 0.6 were regarded to be good and were assigned a $y_{i, 3}=1$. The AVF $f_{3}$ was expressed in log values to plot a suitable curve for the case study and was adjusted so that $y_{i, 3}=0$ for $x_{i, 3}=0.05$, obtaining:

$$
y_{i 3}=f_{3}\left(x_{i 3}\right)= \begin{cases}1+\ln \left(\frac{x_{i 3}}{0.6}\right) \cdot\left(-\ln \left(\frac{0.05}{0.6}\right)\right)^{-1} & \text { if } x_{i 3} \leq 0.6 \\ 1 & \text { if } x_{i 3}>0.6\end{cases}
$$

The resulting graph, with $x_{i, 3}$ on a logarithmic scale, is shown in Fig. 9c. The thresholds values of $U_{3, k}$ and of $V_{3, k}$ in Table 3.c were also inspired from the SQ limits of Table 1. They have the effect in CM case study of lowering the CQI for some soils of intermediate QI values, especially towards $c q_{i}=0.5$. As for $S Q=\mathrm{III}(k=3)$ and IV $(k=4)$ the lower limit for $x_{i, 3}$ is 0.2 . Auxiliary values of $U_{3, k}$ and of $V_{3, k}$ with $U_{3, k}>V_{3, k}$ have been added for $k=3$ to reduce the $c q_{3}$ to 0.6 when $x_{i, 3}<0.2$. Similarly to the procedure for $S Q=V$ $(k=5)$ and VI $(k=6)$, the lower limit for $x_{i, 3}$ is 0.04 ; the values of $U_{3, k}$ and of $V_{3, k}$ for $k=5$ have been taken very near 0.04 with $U_{3, k}>V_{3, k} ; U_{3,6}$ has been taken as 0.04 ; for this logarithmically represented attribute, $V_{3,6}$ has been taken as low as 0.001 ; and the effect of these thresholds on trials seemed adequate.

4. Slope (\%). This is a variable of "more is worse" type. Low $x_{i, 4}$ slopes have little impact, but at grades of about $20-25 \%$ or greater, the soil is not optimal for all farming, and from grades of around $50 \%$ it is suitable only for forestry or recreational use. Therefore, steep slopes were penalised with very negative $y_{i, 4}$ values. The AVF $f_{4}$ adopted is flat with $y_{i, 4}=1$ for $x_{i, 4} \leq 1$, and it decreases according to a simple quadratic pattern as shown in Fig. 9d, in which $y_{i, 4}=0.6$ for $x_{i, 4}=20 \%, y_{i, 4}$ approaches zero as $x_{i, 4}$ approaches $31 \%$, and it declines sharply to below zero as $x_{i, 4}$ rises:

$$
y_{i 4}=f_{4}\left(x_{i 4}\right)= \begin{cases}1 & \text { if } x_{i 4} \leq 1 \\ 1-0.4 \cdot \frac{\left(x_{i 4}-1\right)^{2}}{(20-1)^{2}} & \text { if } x_{i 4}>1\end{cases}
$$

The threshold values of $U_{4, k}$ and of $V_{4, k}$ in Table 3.d were inspired by the SQ limits in Table 1 that exist for $k=1,2, \ldots 7$, but they have been made slightly more permissive (mechanical tillage is possible with some of these values), and the limit $100 \%$ has been added as $V_{4, k}$, to assign soils with higher slope to SQ class 8 with $c q_{i}=0.2$.

5. The "more is worse" type actual erosion index is a qualitative variable with assigned numerical (integer) values, from 0 to 4 corresponding to nil, slight, moderate, severe, and extreme erosion, respectively. In this study the index values ranged from zero to three. In AVF $f_{5}, y_{i, 5}$ decreased with increasing $x_{i, 5}$, such that $y_{i, 5}=0.7$ for $x_{i, 5}=1, y_{i, 5}=0$ for $x_{i, 5}=2$ and $y_{i, 5}=-0.7$ for $x_{i, 5}=3$. The adopted function $f_{5}$ is represented in Fig. $9 \mathrm{e}$ and is:

$$
y_{i, 5}=f_{5}\left(x_{i, 5}\right)= \begin{cases}1-0.3 \cdot\left(x_{i, 5}\right)^{2} & \text { if } x_{i, 5} \leq 1 \\ 0.7-0.7 \cdot\left(x_{i, 5}-1\right) & \text { if } 1<x_{i, 5}\end{cases}
$$

The threshold values of $U_{5, k}$ and of $V_{5, k}$ in Table 3.e have been inspired by the SQ limits of Table 1 for that categorical index $x_{i, 5}$. Auxiliary values of $U_{5, k}$ and of $V_{5, k}$ have been added for $k=5$ to reduce the $c q_{i}$ to 0.4 when $x_{i 5}>3$, and the limit 4 (extreme erosion) has 
been added as $V_{5,6}$, so as to send down soils with higher erosion to SQ class VII $(k=7)$ with $c q_{i}=0.3$.

6. Drainage, a qualitative attribute, was converted to a numerical scale with values ranging from six to zero for excessive, slightly excessive, good, moderately good, slightly poor, poor, and very poor drainage respectively, and from one to six in the case study. A "good" value of $x_{i, 6}=4$ was regarded to be optimum for this AVF, $y_{i, 6}=f_{6}\left(x_{i, 6}\right)$, which was designed with an exponent of 2.8 so that $y_{i, 6}=-1$ for $x_{i, 6}=1$ (poor drainage), the worst value in the case study, as shown in Fig. 9f:

$$
y_{i, 6}=f_{6}\left(x_{i, 6}\right)=1-\frac{2 \cdot\left|4-x_{i, 6}\right|^{2.8}}{(4-1)^{2.8}}
$$

The threshold values of $U_{6, k}$ and of $V_{6, k}$ in Table 3.f were inspired by the SQ limits in Table 1 for a "more is better" type attribute, and for some intermediate classes $(k=3,5)$, auxiliary thresholds are convenient with the algorithm used. The effect of Drainage is important for soil type $i=111$ ("Toyas en suelos turbosos"), which occurs in some depressions in the mountains. For these depressions, the expert qualification for drainage was bad ("poor drainage"). These soils are useful only for ash trees, and hence a negative $y_{i, 6}$ was set for them in the AVF $f_{6}$ curve, with a limit $V_{6,6}=1$. Auxiliary values of $U_{6, k}$ and of $V_{6, k}$ have been added for $k=6$, to reduce the $c q_{i}$ to 0.4 when $x_{i, 6}<2$, and for $k=7$ to reduce the $c q_{i}$ to -1 when $x_{i, 6}$ goes from 1 to 0 .

7. Permeability or $x_{i, 7}$, another qualitative attribute converted to a numerical scale, is defined to range from six to zero for rapid or very rapid, moderately rapid, moderate, moderately slow, slow or low, very slow, and non-permeable qualities, respectively, with values from two to five in the case study. The worst-case scenario was "impermeable", while moderate or moderate to high permeability were the most favourable conditions. Normally, drainage is highly dependent on permeability, but in the case study other effects also had to be considered, such as slope, which facilitates drainage. An exponent of two was chosen for AVF $f_{7}$ to plot a well-shaped curve (Fig. 10a) and it was adjusted to obtain the best value $y_{i, 7}=1$ for $x_{i, 7}=4.7$ and the value $y_{i, 7}=0$ for $x_{i, 7}=1.5$, thus:

$$
y_{i, 7}=f_{7}\left(x_{i, 7}\right)=1-\frac{\left(4.7-x_{i, 7}\right)^{2}}{(4.7-1.5)^{2}}
$$

The threshold values of $U_{7, k}$ and of $V_{7, k}$ in Table 4.a were inspired by the SQ limits of Table 1, for a "more is better" type attribute, and auxiliary thresholds were added for $k=6$ to reduce the $c q_{i}$ to 0.3 when $x_{i, 7}<1$. No permeability $x_{i, 7}$ under 1 exists in the case-study, thus no lower thresholds were used. The effect on the CQI values of Permeability as drawn from Table 1 is noticeably different from that of Drainage. It reduced some high values (e.g. for soils with $i=15,17,19$ ) of QI values for some irrigated soils near Aranjuez in Tajo Valley in the South of CM, with Vegetative Period 11 months, to CQI values $c q_{i}=0.8$, and others to $c q_{i}=0.7$. That effect is a reason to consider both Permeability and Drainage as attributes for QI and CQI methods. In the case study the worst $x_{i, 7}$ is 2 (low permeability), which reduces the $c q_{i}$ towards 0,7 or class III $(k=3)$, but some $U$ and $V$ not used in the case study have been added that would reduce $c q_{i}$ in the sense of Table 4.a if $x_{i, 7}<2$.

8. Stoniness $(\%)$ defines the percentage of area covered by rocks large enough to render tractor tillage difficult. This attribute of "more is worse" type was found to have a low value in most of the case study's soil types (under one, or with values of 0.03 or 0.5 ) or even zero 
(the black squares with a zero value are not shown on the curve in Fig. 10b). It ranged from 10 to 50 in some soils. The limits from the SQ classification in Table 1, 0.01 (for class I), 0.1 to 3 (for class III) and up to 15 , indicate the effect of stoniness on quality. Consequently, a value of 1 was assigned to $x_{i, 8}$ values of 0.01 and lower, expressed on a logarithmic scale in Fig. $10 \mathrm{~b}$ to represent the AVF $f_{8}$ defined in (15). The values decline from 1 for $x_{i, 8}=0.01$, with a neutral tangent function for low values of $x_{i, 8}$, but very high values are penalised, such that $y_{i, 8}$ is equal to $-\infty$ for $x_{i, 8}=100 \%$. The function was adjusted so that $y_{i, 8}$ is zero for $x_{i, 8}=15 \%$, a value that would hinder tillage with normal tractors. As a result, slightly negative $y_{i, 8}$ values were obtained for the $x_{i, 8}$ values of over $15 \%$ found in the case study:

$$
\begin{aligned}
& y_{i, 8}=f_{8}\left(x_{i, 8}\right)=1 \quad \text { if } x_{i, 8} \leq 0.01, \\
& 1-\frac{0.22 \cdot\left(\ln \left(\frac{200}{\pi} \cdot \tan \left(\frac{x_{i, 8} \cdot \pi}{200}\right)\right)-\ln (0.01)\right)^{1.3}}{\left(\ln \left(\frac{200}{\pi} \cdot \tan \left(\frac{0.1 \cdot \pi}{200}\right)\right)-\ln (0.01)\right)^{1.3}} \text { if } x_{i, 8}>0.01
\end{aligned}
$$

The threshold values of $U_{8, k}$ and of $V_{8, k}$ in Table 4 .b have been inspired by the SQ limits of Table 1 for a "more is worse" type attribute. For $(k=3,5)$, auxiliary thresholds were also added to get better interpolation by the algorithm of Fig. 5 and $V_{8,6}=24$ has been added to produce a gradual effect on $x_{i, 8}$ in range $[15,24]$. The effect for the CM case study has been to reduce the $q_{i}$ to a lower $c q_{i}$ when Stoniness is high, such as for soil $i=79$, with $x_{i, 8}=25$ to $c q_{79}=0.3$, for soil $i=82$ with $x_{i, 8}=20$ to $c q_{82}=0.344$ and for soil $i=60$ with $x_{i, 8}=3.3$ to $c q_{60}=0.5975$.

9. Soil sealing and crusting risk. In this attribute of type "more is worse", the conventional index $x_{i, 9}$ that represents the intensity of the effect exhibited values mostly from 0.34 to 2.53 for the soil types in the case study. According to the SQ classification limits (Table 1 ), $x_{i, 9}$ values lower than 1.6 are good, while $x_{i, 9}=2$ is the boundary value for class III or higher. Therefore, AVF $f_{9}$ was designed to cause $y_{i, 9}$ to exhibit a gentle linear decline from 1 to 0.9 for $x_{i, 9}$ values from 0.5 to 1.6 , and then to dip more steeply for higher values of $x_{i, 9}$, to zero for $x_{i, 9}=2$ and approaching -1 for $x_{i, 9}=2.5$. That negative value is derived from experts' opinions for lands with more rain; for the $\mathrm{CM}$ area, in plains having $450 \mathrm{~mm} /$ year (on average, very irregular), more tolerant limits were suggested for the SQ method and adopted just later for the threshold values ( $U$ and $V$ ). In the first trials the AFV $f_{9}$ function was chosen with results not less than 0 , acceptable for $\mathrm{CM}$ region, as:

$$
y_{i, 9}=f_{9}\left(x_{i, 9}\right)= \begin{cases}1 & \text { if } x_{i, 9} \leq 1.6 \\ 1-0.5 \cdot\left(\frac{x_{i, 9}-1.6}{2-1.6}\right)^{2} & \text { if } 1.6<x_{i, 9}<2 \\ 0.5 \cdot 2^{-4 \cdot\left(x_{i, 9}-2\right)} & \text { if } 2 \leq x_{i, 9}\end{cases}
$$

For result more applicable in general for other regions, the following function has been adopted for $f_{9}$, represented in Fig. 10c:

$$
y_{i, 9}=f_{9}\left(x_{i, 9}\right)= \begin{cases}1 & \text { if } x_{i, 9} \leq 0.5 \\ 1-0.1 \cdot\left(\frac{x_{i, 9}-1.6}{1.6-0.5}\right)^{2} & \text { if } 0.5<x_{i, 9}<1.6 \\ 0.9-0.9 \cdot\left(\frac{x_{i, 9}-1.6}{2-1.6}\right)^{0.9} & \text { if } 1.6 \leq x_{i, 9}\end{cases}
$$

The threshold values of $U_{9, k}$ and of $V_{9, k}$ in Table 4.c were inspired by the SQ limits of Table 1, and they have little effect because the values of $x_{i, 9}$ in the CM case study are low and almost all favourable, except for types of soils with $i=23,31,32$. 
10. The $\mathrm{pH}$, attribute $x_{i, 10}$, is best when equal to 7 and worse at acid or basic values; in the case study, it ranged from 4.5 to 8.6. The AVF $f_{10}$ is given in (18) and in Fig. 10d. It was designed as a decreasing parabola covering a total of six $\mathrm{pH}$ values, three on each side of centre. Values decline from a maximum $y_{i, 10}=1$ for $x_{i, 10}=7$ to $y_{i, 10}=0$ when $x_{i, 10}$ is either 4.5 (most acidic value) or 8.5 (most basic value), because such acidic or basic soils are still somehow suitable for farming (see Table 1 e.g.).

$$
y_{i, 10}=f_{10}\left(x_{i, 10}\right)= \begin{cases}1-\frac{\left|7-x_{i, 10}\right|^{3}}{|7-4.5|^{3}} & \text { if } x_{i, 10}<7 \\ 1-\frac{\left|7-x_{i, 10}\right|^{3}}{|9-7|^{3}} & \text { if } x_{i, 10} \geq 7\end{cases}
$$

The best $\mathrm{pH}$ is 7 and in Table 1 there are limits in both sides for the best SQ classes that have inspired the thresholds values for $\left(U_{10, k}, V_{10, k}\right)$ and also for $\left(U_{10, k}^{\prime}, V_{10, k}^{\prime}\right)$ of Table 5 . They exist only for $k=(1,2,3)$, and they contribute mostly to lower the $c q_{i}$ towards 0.8 , of some of the best soils.

11. Carbonates $\left(\% \mathrm{CO}_{3} \mathrm{Ca}\right)$. The attribute $x_{i, 11}$ is ranged from 0 to 36.3 in the case study. Zero values were found in the centre of the region, in sediments originally derived from acidic granite mountains, while values in the 10-37 range were recorded primarily in samples from the North-East of CM. In this attribute of type "more is worse", 10 is a good value, 20 is acceptable and 60 is a relatively poor result. The resulting AVF $f_{11}$, shown in Fig. 10e, is:

$$
y_{i, 11}=f_{11}\left(x_{i, 11}\right)= \begin{cases}1 & \text { if } x_{i, 11} \leq 5 \% \\ 1-0.5 \cdot\left(\frac{x_{i, 11}-5}{30-5}\right)^{1.2} & \text { if } 5 \%<x_{i, 11} \leq 30 \% \\ 1-1 /\left(1+\exp \left(-\frac{x_{i, 11}-30}{30 \cdot 0.5}\right)\right) & \text { if } 30 \%<x_{i, 11}\end{cases}
$$

The threshold values of $U_{11, k}$ and of $V_{11, k}$ in Table 4 .d were inspired by the SQ limits of Table 1 that are only for $k=(1,2,3)$, and they contribute mostly by lowering the $c q_{i}$ of the good soil $i=19$ towards 0.8 .

12. Effective Depth $(\mathrm{cm})$. This important attribute $x_{i, 12}$ is a "more is better" variable that ranged in the case study from 14.7 to $173 \mathrm{~cm}$. A value of $100 \mathrm{~cm}$ is generally agreed to be highly favourable, while $25 \mathrm{~cm}$ may be the lower limit for mechanised farming. Compensation for low depth was incorporated in this function, so that $y_{i, 12}$ was zero for $x_{i, 12}=31.68$ and approached -0.5 for $x_{i, 12}=14.7 \mathrm{~cm}$. AVF $f_{12}$, represented in Fig. 10f, is:

$$
y_{i, 12}=f_{12}\left(x_{i, 12}\right)= \begin{cases}1-1.2 \cdot\left(\frac{120-x_{i, 12}}{120-25}\right)^{2.5} & \text { if } x_{i, 12}<120 \\ 1 & \text { if } 120 \leq x_{i, 12}\end{cases}
$$

The threshold values of $U_{12, k}$ and of $V_{12, k}$ in Table 4.e were inspired by the SQ limits of Table 1, with auxiliary values for $k=5$, and have the effect of lowering the $c q_{i}$ of a reduced number of soils, e.g. to 0.3 for $i=79$.

13. CEC (cmol kg-1) is a "more is better" measure of the cation exchange capacity between the soil and the soil solution, which is related to fertility and bufferability. AVF $f_{13}$, represented in Fig. 11, was designed to be proportional and so as to obtain $y_{i, 13}=1$ when $x_{i, 13}$ is greater than or equal to 22 , a value slightly greater than the higher SQ classification limit in Table 1, providing:

$$
y_{i, 13}=f_{13}\left(x_{i, 13}\right)= \begin{cases}\frac{x_{i, 13}}{22} & \text { if } x_{i, 13} \leq 22 \\ 1 & \text { if } x_{i, 13}>22\end{cases}
$$


The threshold values of $U_{13, k}$ and of $V_{13, k}$ in Table 4 .f for $k=(1,2)$ were inspired by the SQ limits of Table 1, and they contribute slightly to lowering the $c q_{i}$ of some lands.

\section{References}

Aguilar, J., \& Ortíz, R. (1992). Metodología de capacidad de uso agrícola de los suelos. In Sociedad Española de la Ciencia del Suelo, III Congreso Nacional de la Ciencia del Suelo, Pamplona (pp. 281-286).

Allan, D. L. et al. (1995). Soil quality: a conceptual definition. Soil Science Society of America Agronomy News, June 1995 , p. 7.

Anton, J. M., Grau, J. B., \& Sánchez, E. M. (2007a). Compromise programming calibration for financial analysis of firms of a common sector of business, case study for a set of Spanish banks in 1995. Applied Financial Economics 17, 445-461.

Anton, J. M., Grau, J. B., Tarquis, A. M., Saa, A., \& Sánchez, E. M. (2007b). Application of Decision Theory methods for a Community of Madrid soil classification case, extended abstract for ORAFM stream/session in EURO2007 (Prague, July 8-11) accepted and printed in Joumal of Agricultural Science.

Azevedo, A. L., \& Cardoso, J. C. (1962). Soil classification in Portugal and its application in agricultural research. Trans. Comm. IV and V. Int. Soc. Soil. Sci. New Zealand, pp. 473-479.

Belacel, N. (2000). Multicriteria assignment method PROAFTN: Methodology and medical applications. European Joumal of Operational Research, 125, 175-183.

Chang, N. B., Yeh, S. C., \& Wu, G. C. (1999). Stability analysis of grey compromise programming and its application to watershed land-use planning. International Journal of Systems Science, 30(6), 571-589.

De Pauw, E., \& Zoebisch, M. A. (2002). Greenhouse effect and soil degradation. In R. Lal (Ed.), Encyclopedia of soil science (pp. 307-310). New York: Marcel Dekker.

Dent, D., \& Young, A. (1981). Soil survey and land evaluation. London: Allen \& Unwin.

Driessen, P. M., \& Konijn, N. T. (1992). Land-use systems analysis. Wageningen Agricultural University, Department of Soil Science \& Geology: Malang: INRES, 230p.

FAO (1976). A framework for land evaluation. Soils Bulletin No 32. Roma: FAO.

Figueira, J., de Smet, I., \& Brans, J.-P. (2004a). MCDA methods for sorting and clustering problems: PROMETHEE TRI and PROMETHEE CLUSTER. Université Libre de Bruxelles. http://www. ulb.ac.be/polytech/smg/inexpublications.htm, Service de Mathématiques de la Gestion, \#2004/02.

Figueira, J., Tervonen, T., Almeida-Dias, J., Lahdelma, R., \& Salmiken, P. (2004b). SMAA-TRI: a parameter stability analysis method for ELECTRE TRI. In NATO advanced research workshop, 20-24 April 2004, Thessaloniki, Greece.

Figueira, J., Greco, S., \& Ehrgott, M. (Eds.) (2005). Multiple criteria decision analysis, state of the art surveys. Operations research \& management in science. Springer International Series.

Gallardo, J., Almorox, J., \& Hontoria, C. (2002a). Clasificación de la capacidad agrológica de las tierras. 46p. Ed. ETSI Agrónomos, Madrid.

Gallardo, J., Hontoria, C., Almorox, J., \& Saa, A. (2002b). Capacidad Agrológica de las Tierras. Monografía de ETSI Agrónomos, pp. 55, Madrid.

Gallardo, J., Saa, A., Hontoria, C., \& Almorox, J. (2005). Mapa Agrológico: Capacidad Agrológica de las tierras de la Comunidad de Madrid. Ed. D.G. de Urbanismo y Planificación Regional, C.M., pp. 98.

Gregorich, E. G. (2002). Soil quality. In R. Lal (Ed.), Encyclopedia of soil science (pp. 1058-1061). New York: Dekker.

Grau, J. B., Antón, J. M., Saa, A., Díaz, M. C., \& Tarquis, A. M. (2006). Mathematical decision theory applied to soil quality. Poster, 18th world congress of soil science, July 9-15, 2006, Philadelphia, Pennsylvania, USA.

Greco, S., Matarazzo, B., \& Slowinski, R. (1999). The use of rough sets and fuzzy sets in MCDM. In T. Gal, T. Hanne, \& T. Stewart (Eds.), Advances in multiple criteria decision-making (pp. 14.1-14.59). Dordrecht: Kluwer Academic.

Greco, S., Matarazzo, B., \& Slowinski, R. (2001). Rough sets theory for multicriteria decision analysis. European Journal of Operational Research, 129, 1-47.

Gunn, R. H., Beattie, J. A., Reid, R. E., \& Graaff, R. H. M. (Eds.) (1988). Australian soil and land survey handbook: guidelines for conducting surveys. Melbourne: Inkata Press.

Klingebiel, A. A., \& Montgomery, P. H. (1961). USDA agricultural handbook: Vol. 210. Land capability classification. Washington: US Government Printing Office, pp. 21.

Koo, B. K., \& O'Connell, P. E. (2005). An integrated modelling and multi-criteria analysis approach to managing nitrate diffuse pollution: framework and methodology. Science of the Total Environment, 359(13), $1-16$. 
Krcmar, E., Van Kooten, G. C., \& Vertinsky, I. (2005). Managing forest and marginal agricultural land for multiple tradeoffs: compromise on economic, carbon and structural diversity objectives. Ecological Modelling, 185(2-4), 451-468.

Ministerio de Agricultura (1974). Caracterización de la Capacidad Agrologica de los suelos de España. Metodología y Normas. Madrid: Ministerio de Agricultura.

Moraes, M. H., Gomar, P. E., Benez, S. H., \& Barilli, J. (2002). Effects of long-term management systems on soil quality. In 12th international Soil Conservation Organization (ISCO) conference, May 26-31, Beijing (Vol. II, pp. 187-192).

Ocio, J. A., Jiménez Ballesta, R., \& Guerra, A. (1987). Aproximación a la evaluación paramétrica de suelos para distintos usos en Rioja alavesa. Comunicaciones Tomo II: Geología Ambiental y Ordenación del Territorio. III Reunión Nacional Valencia.

Riquier, J., Bramao, D. L., \& Cornet, J. P. (1970). A new system of soil appraisal in terms of actual and potential productivity. FAO Soil Resources, Development and Conservation Service, Land and Water Development Division. FAO Rome, pp. 38.

Romero, C. (1993). Teoría de la decisión multicriterio. Madrid: Alianza Universidad Textos.

Roy, B., \& Bouyssou, D. (1993). Aide Multicritère à la Décision: Méthodes et Cas. Economica. Paris.

Roy, B., \& Figueira, J. (2002). Determining the weights of criteria in the ELECTRE type methods with a revised Simo's procedure. European Joumal of Operational Research, 139, 317-326.

Sánchez, J., Rubio, J. L., Martínez, V., \& Antolín, C. (1984). Metodología de capacidad de uso de los suelos para la Cuenca Mediterránea. In I Congreso Nacional de la Ciencia del Suelo, Madrid (Vol. II, pp. 837848).

Schipper, L. A., \& Sparling, G. P. (2000). Performance of soil condition indicators across taxonomic groups and land uses. Soil Science Society of America Joumal, 64, 300-311.

Strager, M. P., \& Rosenberger, R. S. (2007). Aggregating high-priority landscape areas to the parcel level: an easement implementation tool. Journal of Environmental Management, 82(2), 290-298.

Weintraub, A., Romero, C., Bjørndal, T., Epstein, R., \& Miranda, J. (2007). Handbook of operations research in natural resources. New York: Springer.

Yu, P. L. (1973). A class of solutions for group decisions problems. Management Science, 19, 936-946.

Zeleny, M. (1973). In J. L. Cochrane \& M. Zeleny (Eds.), Compromise programming in multiple criteria decision making (pp. 262-301). Berlin: Springer.

Zornoza, R., Mataix-Solera, J., Guerrero, C., Arcenegui, V., Mataix-Beneyto, J., Morales, J., \& Mayoral, A. M. (2006). Modelling an index for soil quality evaluation based on natural forest soils under Mediterranean conditions. Geophysical Research Abstracts, 8, 03284.

Zopounidis, C., \& Doumpos, M. (2002). Multicriteria classification and sorting methods: a literature review. European Joumal of Operational Research, 138(2), 229-246.

Zopounidis, C., \& Doumpos, M. (2004). Multicriteria decision aid in classification problems. EWG-MCDA Newsletter, Series 3, No. 10, Fall 2004. 